\title{
Surface chemistry of phase-pure M1 MoVTeNb oxide during operation in selective oxidation of propane to acrylic acid
}

\author{
M. Hävecker ${ }^{1}$, S. Wrabetz, J. Kröhnert, L.-I. Csepei, R. Naumann d'Alnoncourt, \\ Y. V. Kolen'ko ${ }^{2}$, F. Girgsdies, R. Schlögl, A. Trunschke \\ Department of Inorganic Chemistry, Fritz Haber Institute of the Max Planck Society, \\ Faradayweg 4-6, 14195 Berlin, Germany \\ ${ }^{1}$ Dept. Solar Energy Research, Helmholtz-Zentrum Berlin / BESSY II, Albert-Einstein-Str. 15, \\ 12489 Berlin, Germany \\ ${ }^{2}$ International Iberian Nanotechnology Laboratory, \\ Avda central 100, Edificio dos Congregados, 4710-229 Braga, Portugal
}

* Corresponding author: e-mail trunschke@ fhi-berlin.mpg.de,

Received 12 May 2011; Revised 7 September 2011; Accepted 12 September 2011; Available online 19 October 2011

\begin{abstract}
The surface of a highly crystalline MoVTeNb oxide catalyst for selective oxidation of propane to acrylic acid composed of the M1 phase has been studied by infrared spectroscopy, microcalorimetry, and in-situ photoelectron spectroscopy. The acid-base properties of the catalyst have been probed by $\mathrm{NH}_{3}$ adsorption showing mainly Brønsted acidity that is weak with respect to concentration and strength of sites. Adsorption of propane on the activated catalyst reveals the presence of a high number of energetically homogeneous propane adsorption sites, which is evidenced by constant differential heat of propane adsorption $\mathrm{q}_{\text {diff,initial }}=57 \mathrm{~kJ} \mathrm{~mol}^{-1}$ until the monolayer coverage is reached that corresponds to a surface density of approximately 3 propane molecules per $\mathrm{nm}^{2}$ at $313 \mathrm{~K}$. The decrease of the heat to $\mathrm{q}_{\mathrm{diff} \text {,initial }}=40 \mathrm{~kJ} \mathrm{~mol}^{-1}$ after catalysis implies that the surface is restructured under reaction conditions. The changes have been analyzed with high-pressure in-situ XPS while the catalyst was working applying reaction temperatures between 323 and $693 \mathrm{~K}$, different feed compositions containing 0 mol.- $\%$ and 40 mol.- $\%$ steam and prolonged reaction times. The catalytic performance during the XPS experiments measured by mass spectrometry is in good agreement with studies in fixed bed reactors at atmospheric pressure demonstrating that the XPS results taken under operation show the relevant active surface state. The experiments confirm that the surface composition of the M1 phase differs significantly from the bulk implying that the catalytically active sites are no part of the M1 crystal structure and occur on all terminating planes. Acrylic acid formation correlates with surface depletion in $\mathrm{Mo}^{6+}$ and enrichment in $\mathrm{V}^{5+}$ sites. In presence of steam in the feed, the active ensemble for acrylic acid formation appear to consist of $\mathrm{V}^{5+}$ oxospecies in close vicinity to $\mathrm{Te}^{4+}$ sites with an element ratio $\mathrm{Te} / \mathrm{V}=1.4$. The active sites are formed under propane oxidation conditions and are embedded in a thin layer enriched in $\mathrm{V}, \mathrm{Te}$, and $\mathrm{Nb}$ on the surface of the structural stable self-supporting $\mathrm{M} 1$ phase.
\end{abstract}

Keywords: MoVTeNb oxide; M1 phase; propane oxidation; acrylic acid; adsorption; microcalorimetry; in-situ XPS; operando; active sites

\section{Introduction}

Alkanes are abundant in fossil resources, such as crude oil and natural gas, and accessible from coal or biomass via synthesis gas chemistry. Oxidative dehydrogenation or selective oxidation of alkanes represent prospective routes to the manufacture of chemical building blocks and intermediates, like olefins and oxygenates, by heterogeneous catalysis. Technical realization of alkane oxidation processes is generally limited due to insufficient productivity. Selectivity to the desired reaction product is the decisive factor in oxidation catalysis in view of an efficient usage of feedstock and energy. Sophisticated catalyst design is required to activate carbon-hydrogen bonds in the non-polar hydrocarbon molecule lowering the activation barrier such that adequate reaction temperatures for subsequent or concurrent oxygen insertion into generally more reactive unsaturated intermediates can be achieved while 
partial or total oxidation to carbon oxides is prevented. Vanadium in oxidation state $5+$ has been suggested to of essential relevance in alkane activation.[1]

$\mathrm{MoVTeNb}$ oxides in the form of an orthorhombic phase, called M1 phase, are active and selective catalysts in ammoxidation of propane to acrylonitrile,[2] oxidation of propane to acrylic acid, $[3,4]$ and oxidative dehydrogenation of ethane to ethylene.[5, 6] MoVTeNb oxides have also been studied in oxidative dehydrogenation of propane,[7] selective oxidation of butane to maleic anhydride,[8] and alcohol oxidation.[9] The complex chemistry of the polycrystalline MoVTeNb oxide catalyst is reflected in its crystal structure.[10-12] The model of the M1 unit cell comprises 44 atoms. Metal-oxygen linkages in the polyhedral network give rise to a channel-like structure with 5-sided pillars filled with $\mathrm{Nb}$, and 6-, and 7-sided channels partially occupied by tellurium oxide entities. Structural building blocks, like the pentagonal $\left\{(\mathrm{Mo}) \mathrm{Mo}_{5}\right\}$ unit, which consists of a central bipyramidal $\mathrm{MO}_{7}$ polyhedron sharing edges with five $\mathrm{MO}_{6}$ octahedra, are well known from supramolecular polyoxometalates representing a link between molecular species in solution and metal oxide networks.[13] Crystal growth of M1 occurs in $c$ direction resulting in prismatic particle morphology with the $\{001\}$ basal plane of the orthorhombic structure arranged perpendicular to the length axis of the cylindrical catalyst particles. Recent concepts directed towards the nature of the active sites on the surface of such catalysts were inspired by the structural specifics of the M1 phase assuming rigid links between $\mathrm{MoO}_{6}$ and $\mathrm{VO}_{6}$ octahedra as sites for propane activation.[14] The peculiar propane activation efficiency of the M1 phase has been attributed to its ability to host $\mathrm{V}^{5+}$ species, the presence of which has been ruled out for the less active M2 phase.[14] The efficiency of M1 in selective oxidation of propane to acrylic acid was originally attributed to the distortion of the octahedral units in the M1 crystal structure on its terminating basal plane arising in particular from the arrangement of heptagonal rings that causes strain.[15] The channels exhibit no detectable porosity due to occupation by tellurium. They open up at the basal plane and have been suggested to be of importance in the reduction and reoxidation of the surface during catalysis.[16, 17] Definite occupations of metal framework M1 positions have been proposed to result in the formation of site-isolated active ensembles on its terminating basal plane that are characterized by close proximity of the required catalytic functions, and, consequently, attributed to high selectivity.[18, 19] In this respect, vanadyl groups with vanadium at the crystallographic positions M3 and M7 have been considered to be particularly responsible for $\mathrm{C}-\mathrm{H}$ activation of propane in the rate-determining abstraction of the first hydrogen atom.

Catalytic experiments trying to verify the assignment of the minority $\{001\}$ faces as location of active sites gave conflicting results.[20-22] Approximately 80\% of the catalyst surface area accounts for the lateral surface of the cylindrical M1 particles. Electron microscopy has shown that the latter is characterized by a stepped morphology pre- sumably resulting in similar terminating metal-oxo arrangements like on the basal plane.[23] STEM of a single M1 crystal viewed in the projection along $\langle 001\rangle$ revealed that the crystal periodicity is broken along the thinnest sections through the mesh of polyhedra. Consequently, the lateral surface of the cylindrical M1 particles is constituted of roughly half-pipes from the formerly closed channels and from wall fragments exposing the inner surface of the channels. This termination model provides a rational explanation for the enriched tellurium content generally observed when surface sensitive methods are applied for analysis of M1.[4, 16, 24-29] The actual termination may differ depending on local cation site occupancy,[30] synthesis method, pretreatment, and reaction conditions. In conclusion, a thorough characterisation of the M1 phase is required to obtain a detailed understanding of its functionality.

We reported on the catalytic properties of a number of phase-pure M1 catalysts with varying chemical composition in the M1 framework.[29] Vanadium and tellurium have been identified as key elements in selective oxidation of propane to acrylic acid, whereas surface enrichment of molybdenum is detrimental with respect to acrylic acid selectivity. These observations have prompted us to suggest a functional model in which the crystal structure of M1 is considered as a host that bears under operation an active thin layer comprising a thickness of about $1 \mathrm{~nm}$ that is connected by chemical bonds to the framework and that is composed of isolated $\mathrm{V}_{\mathrm{x}} \mathrm{O}_{\mathrm{y}}$ moieties embedded in a matrix of $\mathrm{Te}_{\mathrm{x}} \mathrm{O}_{\mathrm{y}}$ surface species. Further elucidation of the actual electronic and molecular structure of the active ensembles on the surface of M1 requires in-situ spectroscopic investigations of the catalyst under operation conditions. In the present work, a well-defined, phase-pure and highly crystalline M1 catalyst was synthesized to study its surface properties before catalysis by adsorption of probe molecules using infrared spectroscopy and microcalorimetry. The response of the terminating layer of the M1 phase to the chemical potential of the gas phase during oxidation of propane to acrylic acid has been investigated applying insitu photoelectron spectroscopy.

\section{Experimental}

\subsection{Synthesis of M1 and reference compounds}

Phase-pure M1 was synthesized using a precipitation-purification procedure.[31] First, $92.86 \mathrm{mmol}$ of $\left(\mathrm{NH}_{4}\right)_{6} \mathrm{Mo}_{7} \mathrm{O}_{24} \cdot 4 \mathrm{H}_{2} \mathrm{O}$ was dissolved at $353 \mathrm{~K}$ in $1.5 \mathrm{~L}$ of MQ water, and then $195.00 \mathrm{mmol}$ of $\mathrm{NH}_{4} \mathrm{VO}_{3}$ was added as a solid to the solution and dissolved. Next, the Mo/Vcontaining solution was cooled to $313 \mathrm{~K}$, and $149.50 \mathrm{mmol}$ of $\mathrm{Te}(\mathrm{OH})_{6}$ was added in solid form and dissolved. In parallel, the $\mathrm{Nb}$-containing solution was prepared by dissolution of $81.25 \mathrm{mmol}$ of $\mathrm{NH}_{4}\left[\mathrm{NbO}\left(\mathrm{C}_{2} \mathrm{O}_{4}\right)_{2}\right] \cdot x \mathrm{H}_{2} \mathrm{O}$ in $0.5 \mathrm{~L}$ of MQ water at $313 \mathrm{~K}$. This solution was then added to the 
$\mathrm{Mo} / \mathrm{V} / \mathrm{Te}$-containing solution and the solution volume was completed to $2.5 \mathrm{~L}$ with MQ water. The slurry with nominal molar ratio Mo: $\mathrm{V}: \mathrm{Te}: \mathrm{Nb}$ of 1:0.3:0.23:0.125 that results after $30 \mathrm{~min}$ stirring at $313 \mathrm{~K}$ was spray-dried using a Büchi B-191 mini spray-dryer. The as-prepared powder was calcined at $548 \mathrm{~K}$ for $1 \mathrm{~h}$ in air flow (flow rate 100 $\mathrm{ml} / \mathrm{min}$ ) and then annealed at $873 \mathrm{~K}$ for $2 \mathrm{~h}$ in Ar flow (flow rate $100 \mathrm{ml} / \mathrm{min}$ ) using a rotary tube furnace (Xerion). In this way, a biphasic M1 and M2 MoVTeNb oxide crystalline product was generated. Next, M1 was separated from $\mathrm{M} 2$ treating the mixed-phase powder with $15 \% \mathrm{H}_{2} \mathrm{O}_{2}$ solution at room temperature via continuous stirring of $400 \mathrm{rpm}$ for $24 \mathrm{~h}$. The used solid to liquid ratio was $0.04 \mathrm{~g} / \mathrm{mL}$. The washed product was collected by vacuum filtration using glass filter (porosity 5), washed with MQ water, and dried at $368 \mathrm{~K}$. Finally, the as-derived sample was heat activated at $873 \mathrm{~K}$ for $2 \mathrm{~h}$ in Ar flow using the rotary tube furnace. The catalyst yield was $41 \%(\sim 54 \mathrm{~g}$; entry M1, internal ID 6059).

The MoV reference oxide was synthesized by a hydrothermal route charging $11.75 \mathrm{~g}$ of $\left(\mathrm{NH}_{4}\right)_{6} \mathrm{Mo}_{7} \mathrm{O}_{24} \cdot 4 \mathrm{H}_{2} \mathrm{O}$, and $4.01 \mathrm{~g} \mathrm{VOSO}_{4} \cdot \mathrm{xH}_{2} \mathrm{O}$ into a 400 $\mathrm{mL}$ autoclave reactor made of Hastelloy C22 (Premex AG) backfilled with $260 \mathrm{~mL}$ of MQ water. The autoclave was sealed, and the precursor system with nominal molar ratio Mo: $\mathrm{V}$ of 1:0.33 was subsequently in-situ homogenized under stirring at $343 \mathrm{~K}$ for $30 \mathrm{~min}$. Then, the autoclave was heated to $423 \mathrm{~K}$ at $1.6 \mathrm{~K} / \mathrm{min}$, and kept at this temperature for $100 \mathrm{~h}$ under constant stirring of $300 \mathrm{rpm}$ and autogenous pressure of $\sim 0.93 \mathrm{MPa}$. After controlled cooling at 1.6 $\mathrm{K} / \mathrm{min}$ to $298 \mathrm{~K}$, the product was collected by centrifugation, washed with MQ water, and dried at $368 \mathrm{~K}$. Finally, the resulting powder was annealed at $673 \mathrm{~K}$ (heating rate: $15 \mathrm{~K} / \mathrm{min}$ ) for $2 \mathrm{~h}$ in Ar flow (flow rate $100 \mathrm{ml} / \mathrm{min}$ ) using a rotary tube furnace (Xerion) (entry $\mathrm{MoVO}_{\mathrm{x}}$, internal ID 8103).

The binary oxides of Mo, $\mathrm{V}$, and $\mathrm{Nb}$ were obtained by spray-drying the aqueous solutions of $\left(\mathrm{NH}_{4}\right)_{6} \mathrm{Mo}_{7} \mathrm{O}_{24} \cdot 4 \mathrm{H}_{2} \mathrm{O}, \quad \mathrm{NH}_{4} \mathrm{VO}_{3}, \quad$ and $\mathrm{NH}_{4}\left[\mathrm{NbO}\left(\mathrm{C}_{2} \mathrm{O}_{4}\right)_{2}\right] \cdot 8.8 \mathrm{H}_{2} \mathrm{O}$, respectively. Molybdenum oxide, vanadium pentoxide, and niobium oxide resulted from stepwise calcination of the dry salt powders at increasing temperatures keeping the final temperature of 853 $\mathrm{K}-873 \mathrm{~K}$ for 6-12 hours. $\mathrm{TeO}_{2}(99.9995 \%)$ was purchased from SIGMA-ALDRICH.

\subsection{Chemical analysis}

Inductively coupled plasma-optical emission spectrometry (ICP-OES, Varian Vista RL spectrometer) was applied to analyze the metal content of M1. The oxygen content was measured via the carrier-gas hot-extraction method (CGHE) using a LECO TC-436 DR/5 analyzer. EDX analysis was done applying a Hitachi S-4800 scanning electron microscope with an EDAX Genesis EDX detector. The measurements were carried out with an accelerating voltage of $10 \mathrm{kV}$.

\subsection{X-ray diffraction}

The M1 catalyst and the reference materials were characterized by powder X-ray diffraction (XRD), using a Bruker D8 ADVANCE diffractometer $\left(\mathrm{Cu} K_{\alpha}\right.$ radiation, secondadry graphite monochromator, scintillation counter), or a STOE STADI P transmission diffractometer $\left(\mathrm{Cu} K_{\alpha 1}\right.$ radiation, primary focusing Ge monochromator, position sensitve detector), respectively. The unit cell parameters of M1 were refined by full pattern fitting according to the Rietveld method using the M1 crystal structure model of DeSanto et al. (orthorhombic, space group Pba2 (no. 32); ICSD 55097)[11], utilizing the Bruker program TOPAS. The degree of crystallinity of M1 was evaluated by the same method, using rutile $\mathrm{TiO}_{2} \mathrm{SRM} 674 \mathrm{~b}$ (NIST, USA) as an internal standard with known weight fraction and crystallinity.

\subsection{Surface area and pore volume determina- tion}

Nitrogen adsorption was carried out at $77 \mathrm{~K}$ on a Quantachrome Autosorb-6B analyzer. Prior to the measurement, the samples were outgassed in vacuum at $423 \mathrm{~K}$ for $2 \mathrm{~h}$. The specific surface area $S_{\mathrm{BET}}$ was calculated according to the multipoint Brunauer-Emmett-Teller method $(\mathrm{BET})$ in the $\mathrm{p} / \mathrm{p}_{0}=0.05-0.3$ pressure range. The total pore volumes were estimated by using the amount of physisorbed nitrogen at a relative pressure $\mathrm{p} / \mathrm{p}_{0}=0.95$.

\subsection{Propane oxidation}

The catalytic activity of the phase-pure M1 catalyst was tested in the oxidation of propane to acrylic acid using a 10-fold parallel reactor set-up (ILS-Premex). For this purpose, $1 \mathrm{~g}$ of powdered catalyst was firstly binder-free pressed under $\sim 185 \mathrm{MPa}$, crushed and sieved to a particle size of $250-355 \mu \mathrm{m}$. Then, $125 \mathrm{mg}$ and $30 \mathrm{mg}$ of each catalyst diluted with about $1 \mathrm{~g}$ of silicon carbide (both 250-355 $\mu \mathrm{m}$ sized), respectively, were loaded into tubular hastelloy reactors with an inner diameter of $4 \mathrm{~mm}$. The feed was composed of $\mathrm{C}_{3} \mathrm{H}_{8}, \mathrm{O}_{2}, \mathrm{H}_{2} \mathrm{O}$ and $\mathrm{N}_{2}$ in a molar ratio of $3: 6: 40: 51$. The reaction was carried out at $653 \mathrm{~K}$ and atmospheric pressure while ranging the gas hourly space velocity (GHSV) between $2500 \mathrm{~h}^{-1}$ and $48000 \mathrm{~h}^{-1}$. Inlet and outlet gases were analyzed by on-line gas chromatography using an Agilent Technologies 7890A GC system. A Plot molesieve column and a Plot Q column coupled with a thermal conductivity detector were used for the analysis of $\mathrm{O}_{2}, \mathrm{~N}_{2}, \mathrm{CO}$, and $\mathrm{CO}_{2}$. Hydrocarbons and oxygenated products were monitored employing a HP-FFAP capillary column and a PlotQ column coupled with a flame ionization detector. The conversion and selectivity were calculated based on the total number of carbon atoms and the products found. The experiments with varying steam content in the 
feed were performed in a single tubular fixed-bed plugflow reactor with an internal diameter of $6.8 \mathrm{~mm}$ using an Agilent Technologies 6890N GC system equipped with PlotQ and Molsieve columns at the thermal conductivity detector and a DB-1 column coupled with a 5975 MS detector.

\subsection{FTIR spectroscopy of adsorbed ammonia}

The IR experiments were carried out using a Perkin Elmer 100 FTIR spectrometer equipped with a liquidnitrogen cooled MCT detector at a spectral resolution of 4 $\mathrm{cm}^{-1}$ and accumulation of 1024 scans. The samples were pressed (125 MPa) into infrared transparent, selfsupporting wafers (typically $20-30 \mathrm{mg} / \mathrm{cm}^{2}$ ), which were placed in an in-situ infrared transmission cell. The IR cell was directly connected to a vacuum system equipped with a gas dosing line. Before adsorption of ammonia, the catalysts were pretreated in vacuum at $423 \mathrm{~K}$ for $2 \mathrm{~h}$. Ammonia was adsorbed at $313 \mathrm{~K}$ increasing the equilibrium pressure up to $7 \mathrm{mbar}$. After 20 minutes, the gas phase was desorbed at $313 \mathrm{~K}$. The spectra have been taken in dynamic vacuum at $313 \mathrm{~K}$, and every $20 \mathrm{~K}$ from $353 \mathrm{~K}$ to $473 \mathrm{~K}$.

\subsection{Microcalorimetry}

Differential heats of adsorption were determined using a MS70 Calvet Calorimeter (SETRAM). The calorimeter was combined with a custom-designed high vacuum and gas dosing apparatus, which has been described in detail before.[32] Sieve fractions of the catalysts as used in the catalytic test were pretreated in the calorimeter cell in vacuum ( $\mathrm{p}=3 \cdot 10^{-8} \mathrm{mbar}$ ) at $423 \mathrm{~K}$ (heating rate $2 \mathrm{~K} \cdot \mathrm{min}^{-1}$ ) for $2 \mathrm{~h}$ and then cooled to room temperature. The cell was then transferred into the calorimeter and heated to the adsorption temperature of $313 \mathrm{~K}$. Propane or propylene were stepwise introduced into the initially evacuated cell, and the pressure evolution and the heat signal were recorded for each dosing step. The adsorption isotherm was derived from the dosed amount and the equilibrium pressure, and the differential heats of adsorption were calculated by converting the signal area into a heat by using the calorimeter's calibration factor and then dividing the heat by the number of molecules adsorbed in this step. Repeated measurements show reproducibility with respect to the isotherm and the heat of adsorption.

\subsection{In-situ photoelectron spectroscopy}

In-situ X-ray photoelectron spectroscopy (XPS) has been performed at the synchrotron radiation facility BESSY II of the HZB (Helmholtz-Zentrum Berlin) using monochromatic radiation of the ISISS (Innovative Station for In Situ Spectroscopy) beamline as a tuneable X-ray source. High pressure XPS spectra were obtained in the presence of reactive gases at elevated temperature using the high pressure end station designed and constructed at the Fritz Haber Institute. Details of the set-up are described elsewhere.[33-36] In brief, $9 \mathrm{mg}$ of MoVTeNb oxide powder was pressed ( 1 ton, disc of diameter $8 \mathrm{~mm}$ ) into a selfsupporting pellet that was mounted inside a reaction cell onto a sapphire sample holder approximately $1200 \mu \mathrm{m}$ in front of the $1^{\text {st }}$ aperture of a differentially pumped

Table 1. Chemical composition, structural, and textural characteristics of phase-pure M1 MoVTeNb oxide activated in Ar at $873 \mathrm{~K}$ (catalyst $\mathrm{ID}=6059)$ and after $600 \mathrm{~h}$ time on stream in oxidation of propane at $673 \mathrm{~K}$ applying the feed $\mathrm{C} 3 / \mathrm{O}_{2} / \mathrm{H}_{2} \mathrm{O} / \mathrm{N}_{2}=2.5 / 6.3 / 40.3 / 50.9(\mathrm{vol} .-\%)$ at a GHSV $=1200 \mathrm{ml} \mathrm{gcat}^{-1} \mathrm{~h}^{-1}$ (catalyst ID=6693)

\begin{tabular}{|c|c|c|}
\hline & M1 activated in $\mathrm{Ar}$ & M1 used in $\mathrm{C}_{3} \mathrm{H}_{8}$ oxidation \\
\hline Oxide stoichiometry, normalized to $\mathrm{Mo}^{2}$ & $\mathrm{Mo}_{100} \mathrm{~V}_{026} \mathrm{Te}_{0.09} \mathrm{Nb}_{0.17} \mathrm{O}_{40}$ & n.d. \\
\hline Metal stoichiometry (EDX), normalized to $\mathrm{Mo}^{\mathrm{b}}$ & $\mathrm{Mo}_{1} \mathrm{~V}_{026} \mathrm{Te}_{0.10} \mathrm{Nb}_{0.22}$ & $\mathrm{Mo}_{1} \mathrm{~V}_{0.27} \mathrm{Te}_{0.10} \mathrm{Nb}_{0.24}$ \\
\hline \multirow{3}{*}{ Unit cell parameters, Pba2 (No. 32), $\AA$} & $a=21.1255(2)$ & $a=21.1352(16)$ \\
\hline & $b=26.6145(2)$ & $b=26.6287(21)$ \\
\hline & $c=4.0137(2)$ & $c=4.01299(22)$ \\
\hline Domain size $D_{\text {XRD, }} \mathrm{nm}$ & 55.6 & 61.0 \\
\hline Degree of crystallinity ${ }^{c}$, wt.\% & 85.6 & n.d. \\
\hline Surface area $S_{\text {BET }}{ }^{d}, \mathrm{~m}^{2} / \mathrm{g}$ & 8.8 & n.d. \\
\hline Total pore volume ${ }^{\mathrm{d}}, \mathrm{cm}^{3} / \mathrm{g}$ & 0.02 & n.d. \\
\hline Monolayer adsorption capacity of propane $\mathrm{N}_{\operatorname{mana}}{ }^{e}, \mu \mathrm{mol} \mathrm{g}_{\text {cat }}^{-1}$ & 43 & 39 \\
\hline Langmuir constant $K^{\mathrm{e}}, \mathrm{hPa}^{-1}$ & $0.111(6)$ & $0.042(5)$ \\
\hline Surface area $S_{\text {Langmuir }}{ }^{e}, \mathrm{~m}^{2} / \mathrm{g}$ & 9.2 & 8.3 \\
\hline Heat of propane adsorption $q_{\text {diffinitial }} \mathrm{kJ} / \mathrm{mol}$ & 57 & 40 \\
\hline Heat of propene adsorption $q_{\text {diff,initial, }} \mathrm{kJ} / \mathrm{mol}$ & 53 & 55 \\
\hline
\end{tabular}


Table 2. Properties of binary and ternary reference oxides

\begin{tabular}{lllll}
\hline $\begin{array}{l}\text { Reference } \\
\text { oxide }\end{array}$ & $\begin{array}{l}\text { Catalyst } \\
\text { ID }\end{array}$ & $\begin{array}{l}\text { Phase } \\
\text { composition }\end{array}$ & $\begin{array}{l}\text { Surface area } \\
S_{\text {BET }}\left(\mathrm{m}^{2} / \mathrm{g}\right)\end{array}$ & $\begin{array}{l}\text { Propane } \\
\text { adsorption } \\
q_{\text {diffinitial }}(\mathrm{kJ} / \mathrm{mol})\end{array}$ \\
\hline $\mathrm{MoO}_{3}$ & 6267 & $\alpha-\mathrm{MoO}_{3}$ & 1.8 & 45 \\
$\mathrm{~V}_{2} \mathrm{O}_{5}$ & 7304 & $\alpha-\mathrm{V}_{2} \mathrm{O}_{5}$ & 2.9 & 55 \\
$\mathrm{Nb}_{2} \mathrm{O}_{5}$ & 7236 & $\mathrm{~T}^{-\mathrm{Nb}_{2} \mathrm{O}_{5}}$ & 42.0 & 38 \\
$\mathrm{TeO}_{2}$ & 7604 & $\alpha-\mathrm{TeO}_{2}$ & 1.4 & 90 \\
$\mathrm{MoVO}_{x}$ & 8103 & $\begin{array}{l}\text { Nano-crystalline, } \\
\text { orthorhombic }\end{array}$ & 35.7 & 40 \\
& & & \\
\hline
\end{tabular}

electrostatic lens system. The home-built electron lens serves as the input system for a (modified) commercial hemispherical electron analyzer (PHOIBOS 150, Specs$\mathrm{GmbH})$. Gases are introduced to the cell via calibrated mass flow controllers, heating is provided by a NIR laser ( $808 \mathrm{~nm}, \mathrm{cw})$ at the rear of the sample, and the temperature is monitored by a thermocouple attached directly to the sample surface. Mixtures of $\mathrm{O}_{2} / \mathrm{C}_{3} \mathrm{H}_{8} / \mathrm{He}$ and $\mathrm{O}_{2} / \mathrm{C}_{3} \mathrm{H}_{8} / \mathrm{H}_{2} \mathrm{O}_{\text {(g) }}$ with volume flows of $2 \mathrm{sccm} / 1 \mathrm{sccm} / 2.8 \mathrm{sccm}$ have been introduced resulting in a total pressure in the XPS chamber of $25 \mathrm{~Pa}$ and the heating rate was $5 \mathrm{~K} / \mathrm{min}$ up to the final temperature of $693 \mathrm{~K}$. Core level spectra of O1s, V2p, Mo3d, Te3d, C1s have been obtained with a constant kinetic energy of the photoelectrons of $150 \mathrm{eV}$ resulting in an inelastic mean free path (IMFP) of approximately $0.6 \mathrm{~nm}$, i.e. in a high surface sensitive mode. For comparison, the dimension of one unit cell of the M1 structure is $2.1 \times 2.7 \times 0.4 \mathrm{~nm}$. The majority of electrons (63\% in a model neglecting elastic scattering) is released within this depth. The result is a significant increase in surface sensitivity in synchrotron based XPS compared to the excitation with a regular laboratory X-ray source (e.g. Mg K- $\alpha$ X-ray tube) where the IMFP is estimated to be $1.6 \mathrm{~nm}$ and $2.1 \mathrm{~nm}$ for $\mathrm{V} 2 \mathrm{p}$ and Mo3d core level excitation, respectively, due to the higher kinetic energy of photoelectrons.[37] The XPS spectra were normalized by the storage ring current and by the photon energy dependent incident photon flux, which was measured prior to the experiments using an $\mathrm{Au}$ foil. The photon flux obtained was corrected for higher diffraction orders that contribute only to the background but not to the peak intensity in XPS. The binding energy (BE) scale was calibrated with respect to the valence band onset. V2 $\mathrm{p}_{3 / 2}$ peak deconvolution and quantitative element abundance calculations were performed using CASA data analysis software (Neil Farley, www.casaxps.com) evaluating normalized core level intensities after subtraction of a Shirley type background taking into account the photon energy dependence of the atomic subshell photo-ionization cross sections.[38] Furthermore, $\mathrm{X}$-ray induced oxygen Auger Electron spectra have been recorded with photon energy of $650 \mathrm{eV}$.

The error bar of the absolute elemental composition can be estimated up to $20 \%$ due to uncertainties in the monochromatic photon flux, cross sections and peak areas. However, only the uncertainty in the peak area determination contributes to relative uncertainties in an experimental series and therefore, the relative error bar in the XPS figures can be estimated to be approximately $2 \%$.

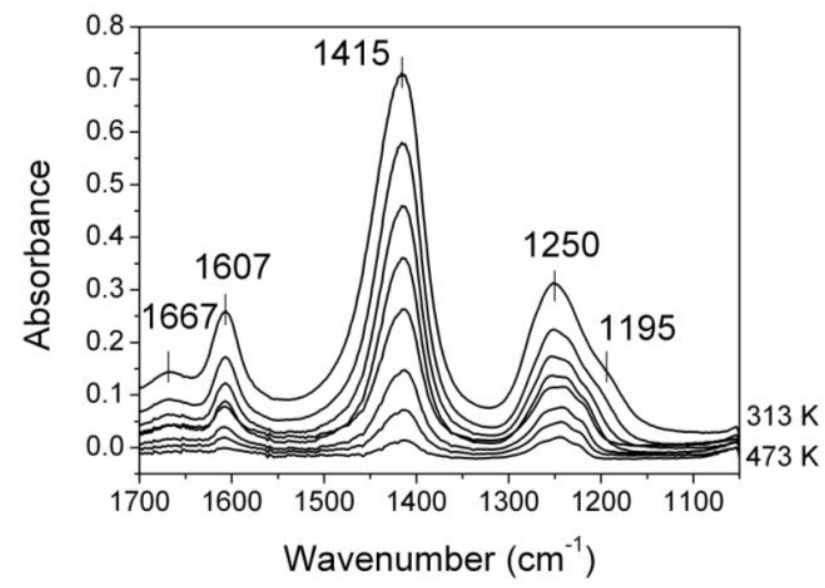

Figure 1. FTIR spectra of ammonia adsorbed on the reference orthorhombic MoV oxide (ID 8103). The spectra have been taken in dynamic vacuum at $313 \mathrm{~K}$, and every $20 \mathrm{~K}$ from $353 \mathrm{~K}$ to $473 \mathrm{~K}$ (from top to bottom plotted with offset for clarity).

The gas phase composition was monitored by online mass spectrometry simultaneously to the surface charac terization of the catalyst. A proton transfer reaction mass spectrometer (PTR-MS, IONICON) was connected to the exhaust line of the XPS cell to determine online the abundance of acrylic acid.

\section{Results}

\subsection{General properties of M1 and reference compounds}

Chemical, structural and textural details of the M1 catalyst are summarized in Table 1 . The phase purity was verified by XRD. The XRD patterns (not shown) are exclusively characterized by reflections that arise from the M1 phase. No peaks were detected related to the presence of any other crystalline phase, especially not the most likely M2 phase. The lattice parameters determined by Rietveld analysis are given in Tab. 1. Slight differences compared to lattice constants reported in the literature arise from variations in the chemical composition.[11] We have shown before that the metal content of phase-pure M1 is not restricted to a specific molar ratio of the metals in the structure, but covers a certain array in the quinternary phase diagram.[29] The degree of crystallinity of the M1 catalyst is 85.6 wt. $\%$ as determined from XRD measurements (Tab. 1). Due to relaxation of the crystal structure on the fringes of the crystal, diffraction in the surface region of any crystalline material is different from the bulk. Consequently, the degree of crystallinity never achieves $100 \mathrm{wt}$ $\%$.[39] Compared to $~ 89.5$ wt.- $\%$ degree of crystallinity certified for the rutile standard, the crystallinity of the M1 catalyst is quite high, which is also reflected in a comparatively low specific surface area (Tab.1). The nitrogen adsorption isotherm (not shown) is characteristic of a 


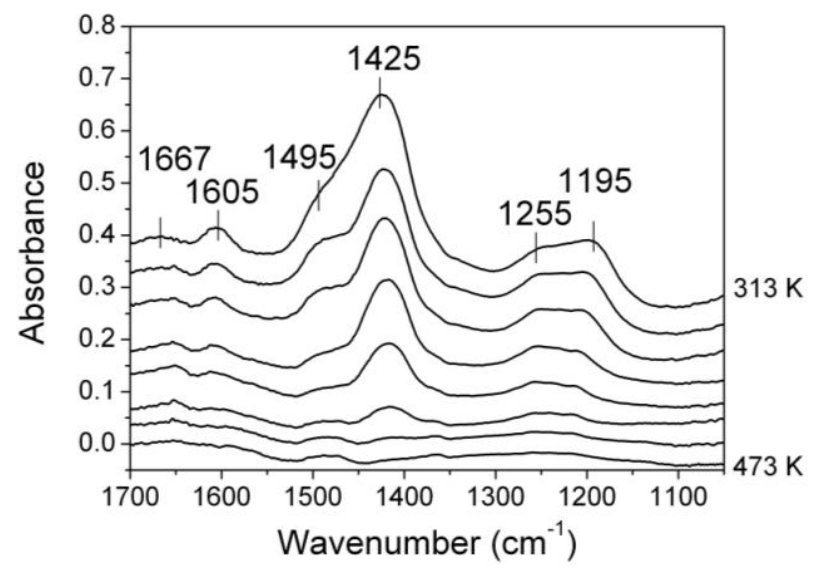

Figure 2. FTIR spectra of ammonia adsorbed on M1 MoVTeNb oxide (ID 6059). The spectra have been taken in dynamic vacuum at 313 , and every $20 \mathrm{~K}$ from $353 \mathrm{~K}$ to $473 \mathrm{~K}$ (from top to bottom plotted with offset for clarity).

macroporous material. The void volume enclosed by the particle aggregates comprises approximately $0.02 \mathrm{~cm}^{3} / \mathrm{g}$. For reference, binary and ternary oxides have been included in the studies by microcalorimetry and infrared spectroscopy. Phase composition and specific surface area of these oxides are given in Table 2. With the exception of niobia and the ternary MoV oxide, the specific surface areas of the reference oxides are very low. According to the XRD patterns, the MoV oxide is nano-crystalline. Rietveld refinement resulted in an orthorhombic M1-like structure when anisotropic peak broadening was allowed in the fitting routine.

\subsection{Adsorption of probe molecules on the acti- vated catalyst}

\subsubsection{Adsorption of ammonia}

FTIR spectra taken during temperature-programmed desorption of ammonia adsorbed on the reference ternary MoV oxide are shown in Fig. 1. The broad peak in the range between 1500 and $1350 \mathrm{~cm}^{-1}$ is attributed to the asymmetric deformation vibration of ammonium ions formed by reaction of $\mathrm{NH}_{3}$ with Brønsted acid sites. The band of the corresponding symmetric deformation vibration is found as a weak feature near $1670 \mathrm{~cm}^{-1}$. The ammonium peak on the quinternary M1 oxide is more complex showing a shoulder at $1495 \mathrm{~cm}^{-1}$, which is not existent on MoV oxide (Fig. 2). This additional component is due to the presence of tellurate, because ammonia adsorption on tellurium oxide resulted in a peak at $1480 \mathrm{~cm}^{-1}$ (spectrum not shown). The diagnostic bands due to ammonium ions adsorbed on $\mathrm{MoO}_{3}$ and $\mathrm{V}_{2} \mathrm{O}_{5}$ occur between 1415 and 1425 $\mathrm{cm}^{-1}$.[40] Adsorbed ammonia on niobium pentoxide leads to a band at $1433 \mathrm{~cm}^{-1}$.[41]

Lewis acid sites on the surface of the two oxides are indicated by peaks corresponding to symmetric and asym
Table 3. Acidity of M1 and MoV oxide probed by ammonia adsorption

\begin{tabular}{lll}
\hline & M1 (6059) & MoV oxide (8103) \\
\hline Normalized integrated $\mathrm{NH}_{4}{ }^{+}$band area & 0.63 & 1.75 \\
Concentration of adsorbed $\mathrm{NH}_{4}{ }^{+}(\mathrm{mmol} / \mathrm{g})$ & 0.04 & 0.11 \\
Concentration of adsorbed $\mathrm{NH}_{4}^{+}\left(\mathrm{mmol} / \mathrm{m}^{2}\right)$ & 0.004 & 0.003 \\
Brønsted sites/Lewis sites ratio & 2.34 & 2.29 \\
\hline
\end{tabular}

metric deformation vibrations of coordinatively bonded ammonia molecules at $1300-1150$ and $1607 \mathrm{~cm}^{-1}$, respectively. The different chemical composition of the two oxides is reflected in a different fine structure of these bands. The Brønsted / Lewis acidity ratio based on the normalized integrated peak areas is similar for the two catalysts. The value points to the predominance of hydroxyl groups on the surface at the temperature of the measurement (Tab. 3).

The concentration of Brønsted acid sites, which has been estimated applying the extinction coefficient $\varepsilon=16 \mathrm{~cm} \cdot \mu \mathrm{mol}^{-1}$ determined for the asymmetric deformation vibration of ammonium ions adsorbed on $\mathrm{Al}_{2} \mathrm{O}_{3}$ supported vanadia, [42] is smaller on M1 than on MoV oxide (Tab. 3). The difference is mainly due to the difference in the specific surface area of these two mixed oxides. The overall acid strength is quite low, but slightly increased over MoV oxide that shows still some traces of adsorbed ammonia after evacuation at $473 \mathrm{~K}$, whereas complete desorption of $\mathrm{NH}_{3}$ has been achieved on M1 after evacuation at $453 \mathrm{~K}$. Similar trends were observed by pyridine and ammonia adsorption on chemically related systems composed of a mixture of phases.[43-45] The weak acid sites on MoVTeNb oxide might be responsible for undesired C$\mathrm{C}$ bond splitting reactions that lead to the formation of acetic acid and carbon oxides. The results suggest that acidbase catalyzed reaction pathways cannot be excluded but may play perhaps a minor role in the reaction network of propane oxidation over M1.

\subsubsection{Adsorption of propane and propene at $313 \mathrm{~K}$}

Microcalorimetry was used to study the adsorption of propane and propylene at $313 \mathrm{~K}$ over M1 before and after use in oxidation of propane to acrylic acid. The differential heat of propane adsorption as a function of the amount of adsorbed propane is shown in Figure 3. The coverage has been normalized to the specific BET surface area of the catalyst measured by nitrogen adsorption (Tabs. 1 and 2). The dotted line at $14 \mathrm{~kJ} \cdot \mathrm{mol}^{-1}$ marks the heat of condensation of propane. For the activated M1 catalyst, the initial differential heat of propane adsorption is $57 \pm 2 \mathrm{~kJ} \cdot \mathrm{mol}^{-1}$ suggesting the existence of a specific interaction of the molecule with the oxide. The heat remains almost constant with increasing coverage that demonstrates the presence of homogeneously distributed and energetically uniform adsorption sites on the activated M1 catalyst surface (Fig. 3, filled squares). At higher coverage $\left(>3.5 \mu \mathrm{mol} \cdot \mathrm{m}^{-2}\right)$ the heat decreases rapidly and reaches the heat of condensation 


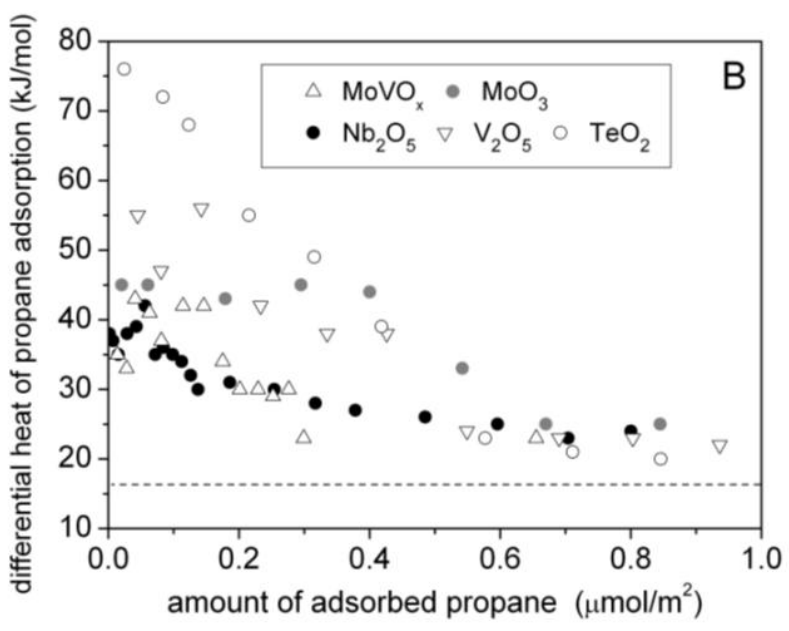

Figure 3. A: Adsorption of propane on the reference oxides, and on M1 MoVTeNb oxide before (catalyst ID 6059, filled squares) and after propane oxidation (catalyst ID $=6693$, open squares; reaction conditions: $\mathrm{T}=673 \mathrm{~K}$, feed $\mathrm{C} 3 / \mathrm{O}_{2} / \mathrm{H}_{2} \mathrm{O} / \mathrm{N}_{2}=3 / 6 / 40 / 51$ vol. $-\%$, varying GHSV=1500-4600 $\mathrm{ml} \mathrm{g}_{\text {cat }}^{-1} \mathrm{~h}^{-1}$, TOS 192 h). The differential heat of propane adsorption is plotted as a function of coverage normalized to the specific surface area. B: The adsorption of propane on the reference oxides is drawn to a larger scale between 0 and $1 \mu \mathrm{mol} / \mathrm{m}^{2}$.

of propane indicating that in this range the monolayer is completed and multilayer adsorption proceeds. Usage of M1 in the oxidation of propane to acrylic acid changes the surface properties substantially (Fig. 3, open squares). Propane reveals less strong interaction with the surface of the used catalyst, which is reflected in a decreased differential heat of propane adsorption of approximately $40 \pm 2 \mathrm{~kJ} \cdot \mathrm{mol}^{-1}$. The energetic homogeneity of the propane adsorption sites, however, remains apparently unchanged. The decline in adsorption strength might be caused by surface modification during propane oxidation. Catalyst handling, such as cooling down the catalyst after propane oxidation, removal from the reactor and storage may affect the surface state. It should be noted at this point that almost no induction period is observed in propane oxidation over M1 in the time frame of GC analysis ( $25 \mathrm{~min}$ ) and that re-use of the same catalyst shows reproducible results without noticeable induction period even after storage of the catalyst in a laboratory environment for more than one year. These facts imply that the quenched state of the catalyst surface may be close to that of the actual working surface.

Compared to M1, the density of propane adsorption sites at which the molecule interacts more specifically with the solid surface, i.e., the released heat is substantially higher than the heat of condensation, seems to be considerably lower on the reference binary and ternary oxides (Fig. 3 A). For the purpose of clarity the range of coverage between 0 and $1 \mu \mathrm{mol} \cdot \mathrm{m}^{-2}$ is shown on a larger scale in Fig. $3 \mathrm{~B}$. The initial heat released upon adsorption of propane over $\mathrm{Mo}, \mathrm{V}, \mathrm{Nb}$, and the ternary MoV oxide is found between 55 and $35 \mathrm{~kJ} \cdot \mathrm{mol}^{-1}$ (Tab. 2). The measured values are in agreement with heats reported for the adsorption of propane over $\mathrm{V}_{2} \mathrm{O}_{5}$.[46] $\mathrm{TeO}_{2}$ exhibits the highest initial differential heat $\left(90 \pm 10 \mathrm{~kJ} \cdot \mathrm{mol}^{-1}\right)$ of all materials studied in the present work. The heat profiles indicate that the differential heat decreases with increasing coverage. This observation is interpreted in terms of energetically heterogeneously distributed propane adsorption sites on the surface of the reference oxides and that the strongest adsorption sites are occupied first at the lowest equilibrium pressures.

In all experiments, propane could be completely desorbed by evacuation at the adsorption temperature to a final pressure of $3 \times 10^{-8}$ mbar. The resulting integral heat of desorption was comparable to the sum of the heats for the individual adsorption steps. This indicates that propane is reversibly adsorbed on M1 and the binary and ternary reference oxides. Reversible propane adsorption is also in accordance with the observed heat of adsorption and the time constants of the individual integral heat signals (250 $350 \mathrm{~s})$ that correspond to the time constant of the calorimeter.

The occurrence of extended plateaus in the heat profiles of propane adsorption over the activated and the used M1 catalyst suggest that the adsorption sites of propane are energetically nearly equivalent. Therefore, the Langmuir adsorption equation has been applied to model the measured adsorption isotherms (Fig. 4, equation(1)),[47, 48]

$$
N_{a d s}=N_{\text {mono }} \frac{K p}{1+K p}
$$

where $\mathrm{N}_{\mathrm{ads}}$ is the amount of propane adsorbed at equilibrium pressure $\mathrm{p}, \mathrm{N}_{\text {mono }}$ is the monolayer adsorption capacity, and $K$ is the Langmuir constant. The equilibrium pressure under which the monolayer of adsorbed propane is completed was estimated based on the inflection point at which the differential heat of propane drops to the heat of condensation (Tab. 1). The adsorption isotherms are well correlated by the Langmuir model if the fit was restricted to the monolayer capacity (Fig. 4). The Langmuir constant $K$ is a measure of the strength of interaction between the adsorbate and the adsorbent. In agreement with the lower heat of adsorption, the Langmuir constant that results for the used catalyst is significantly reduced compared to the constant obtained for the fresh M1 (Tab. 1). The area occupied per propane molecule that has been measured based on adsorption isotherms over various solid surfaces is on average $36 \AA^{2}$.[49] Assuming a cross-sectional area of $35.5 \AA^{2}$ determined for propane adsorption at $209 \mathrm{~K}$ on ammonium phosphomolybdate,[50] which is chemically related to $\mathrm{MoVTeNb}$ oxide, specific surface areas of activated and used M1 have been calculated based on the Langmuir adsorption isotherms of propane at $313 \mathrm{~K}$ (Tab. 1). The surface area of the activated M1 is in very good agreement with the surface area measured by nitrogen adsorption applying the BET method. In accordance with the only slight changes in particle size and the unchanged morphology 


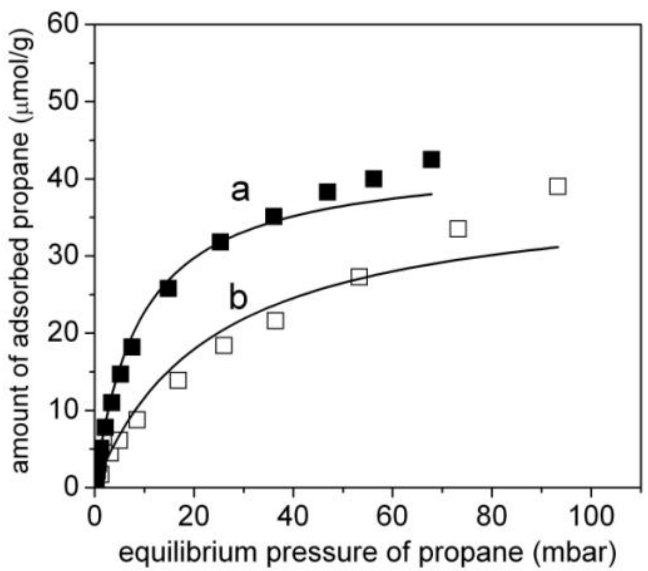

Figure 4. Adsoption isotherm of propane over M1 a) before catalysis (filled squares, catalyst ID 6059) and b) after catalysis (open squares, catalyst ID 6693) measured at $313 \mathrm{~K}$. The solid lines correspond to the Langmuir fit (Equation (1), $R^{2}=0.99115$ for a) and $\mathrm{R}^{2}=0.95148$ for $\mathrm{b}$ )).

before and after propane oxidation, the surface areas based on propane adsorption are similar for the activated and the used M1 catalyst (Tab. 1). The good agreement between the surface area measured by nitrogen and propane adsorption clearly indicates that propane interacts with the entire M1 surface, but, in accordance with the magnitude of the heat of adsorption, propane adsorption is specific. The propane molecules are adsorbed on sites of equal strength until a monolayer is reached, which corresponds to a surface density of approximately three propane molecules per $\mathrm{nm}^{2}$. The absence of any steps in the plot of the heat as a function of coverage definitely evidences that there are no fractions of the M1 surface that show particular interaction with propane at ambient temperature. In particular, no prominent adsorption property of the $a b$ plane becomes evident from our measurements.

Propylene adsorption over phase pure M1 generates an initial heat of adsorption of approximately $55 \pm 2 \mathrm{~kJ} \cdot \mathrm{mol}^{-1}$ (Fig. 5 A, filled circles). The heat profile exhibits two steps before the measured value finally approaches the heat of condensation at higher coverage. Apparently, the surface of M1 provides two different specific adsorption sites for propylene. With respect to the number, these sites seem to be evenly divided. The differential heat of propylene adsorption in the range of low coverage up to $2 \mu \mathrm{mol} \cdot \mathrm{m}^{-2}$ is similar to the heat measured for propane adsorption. Between 2 and $5 \mu \mathrm{mol} \cdot \mathrm{m}^{-2}$ a significant lower heat of 41 $\mathrm{kJ} \cdot \mathrm{mol}^{-1}$ was registered. Some of the stronger adsorption sites remain unchanged by the usage of M1 in propane oxidation (Fig. 5 A, open circles), but weaker adsorption sites are also generated by the usage of the catalyst, characterized by $41 \mathrm{~kJ} \cdot \mathrm{mol}^{-1}$ (between 1 and $3 \mu \mathrm{mol} \cdot \mathrm{m}^{-2}$ ) and 37 $\mathrm{kJ} \cdot \mathrm{mol}^{-1}$ (between 3 and $6.5 \mu \mathrm{mol} \cdot \mathrm{m}^{-2}$ ). Re-adsorption of propylene after desorption by evacuation at $313 \mathrm{~K}$ results in
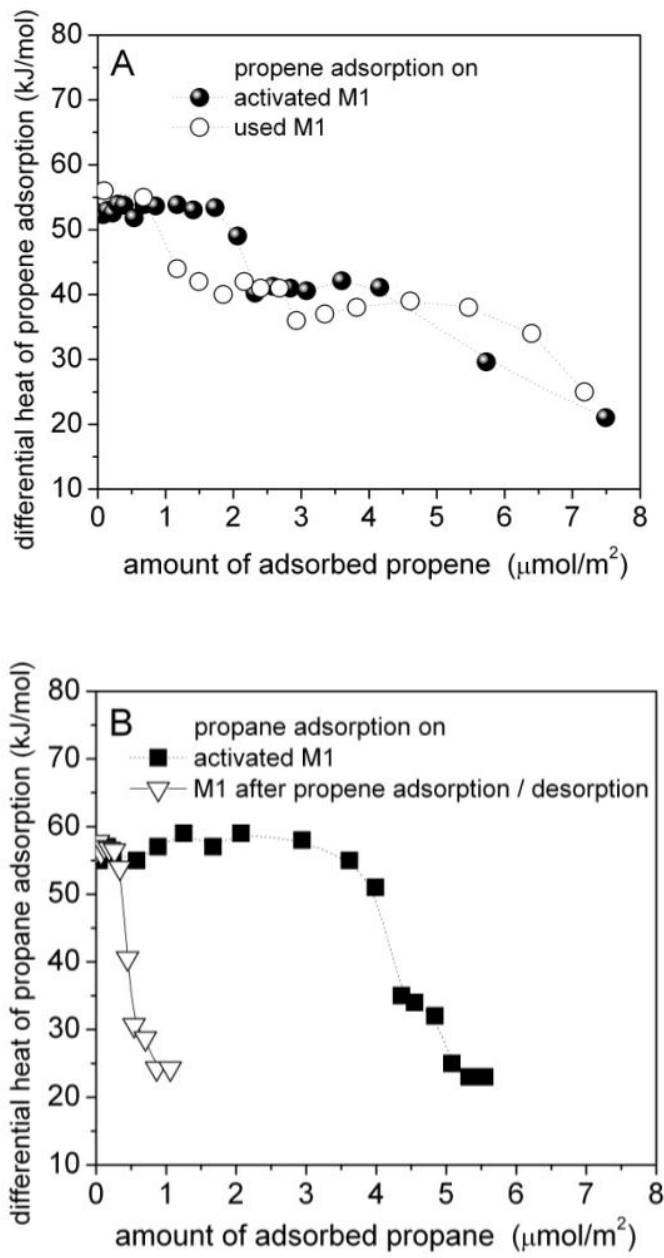

Figure 5. A: Adsorption of propene on M1 MoVTeNb oxide before (catalyst ID 6059, filled circles) and after propane oxidation (catalyst ID 6693, open circles; reaction conditions of propane oxidation: see Fig. 3). B: Adsorption of propane on activated (fresh) M1 MoVTeNb oxide (catalyst ID 6059, filled squares) and after adsorption and subsequent desorption of propene at $313 \mathrm{~K}$ (open triangles). The differential heat of adsorption is plotted as a function of coverage normalized to the specific surface area.

drastic changes in the adsorption isotherm and differential heat profile indicating that a substantial number of adsorption sites have been lost by irreversible adsorption (Figures not shown). The time constants of the individual integral heat signals of propylene adsorption on fresh M1 range between 550 and $400 \mathrm{~s}$ for low coverage $\left(<0.3 \mu \mathrm{mol} \cdot \mathrm{m}^{-2}\right)$. This value significantly deviates from the time constant of the calorimeter $(250-350 \mathrm{~s})$ confirming the irreversibility. At higher coverage the time constants correspond to the time constant of the calorimeter indicating reversibility. Fig. 5 B illustrates that propylene adsorption on M1 at 313 $\mathrm{K}$ leaves only very few of the original propane adsorption sites behind. Presumably, irreversible adsorbed propylene cannot be removed by reaction or desorption at such a low temperature. 


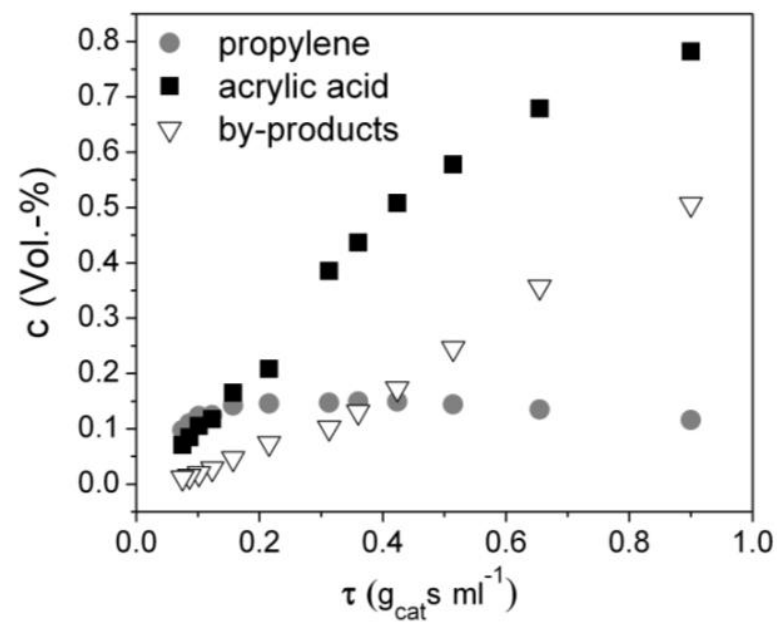

Figure 6. Concentration of selective oxidation products propene and acrylic acid and by-products acetic acid, $\mathrm{CO}_{2}$, and $\mathrm{CO}$ as a function of the contact time measured in propane oxidation over M1 MoVTeNb oxide (catalyst ID 6059) at $\mathrm{T}=653 \mathrm{~K}$ and a molar ratio of the feed gases $\mathrm{C}_{3} \mathrm{H}_{8} / \mathrm{O}_{2} / \mathrm{H}_{2} \mathrm{O} / \mathrm{N}_{2}=3 / 6 / 40 / 51$.

\subsection{Selective oxidation of propane to acrylic acid}

The catalytic properties of the phase pure M1 have been probed in direct oxidation of propane to acrylic acid applying a fixed molar ratio of propane : oxygen : steam of $3: 6: 40$ in the feed. Fig. 6 reports the concentration of the main reaction products propylene and acrylic acid in the effluent gas with increasing contact time at $653 \mathrm{~K}$. The concentration of undesired partial and total oxidation byproducts acetic acid, carbon monoxide, and carbon dioxide is shown as sum. Other by-products have not been observed at this reaction temperature. Propylene and acrylic acid are the dominating reaction products at short contact times. With increasing contact times, the fraction of partial and total by-products rises, confirming that a complex network of consecutive and parallel reactions happens on the M1 surface. As a consequence, a maximum yield to acrylic acid of approximately $31 \mathrm{~mol}-\%$ is achieved at medium contact times on this particular M1 catalyst. The experiment demonstrates that the present M1 exhibits a catalytic performance similar to related MoVTeNb oxide catalysts.[3, 51, 52] It is notable that the phase-pure M1 MoVTeNb oxide catalyst is structurally absolutely stable under conditions of prolonged propane oxidation at $673 \mathrm{~K}$ for more than $600 \mathrm{~h}$ time on stream (TOS) revealing no change of the phase composition during the prolonged reaction time. The average domain size determined by XRD increases slightly from $56 \mathrm{~nm}$ in the activated catalyst to $61 \mathrm{~nm}$ in the catalyst tested in propane oxidation (Tab. 1). The metal stoichiometry before and after catalysis, which has been compared using multi-spot EDX analysis (Tab. 1), remains unmodified in the limits of the error bar of the experimental method.

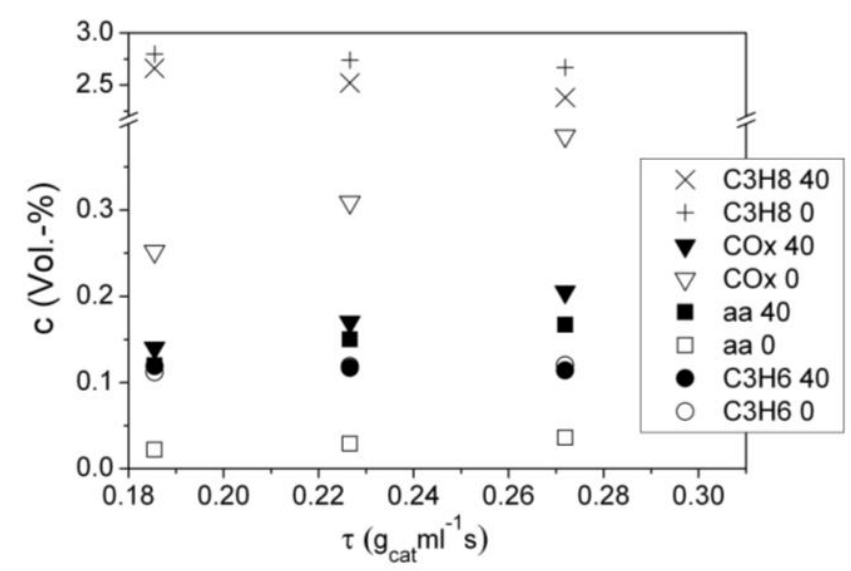

Figure 7. Concentration of propane and reaction products acrylic acid (aa, squares), propylene (circles), and carbon oxides (triangles) in the range between $\tau=0.14 \mathrm{~g} \cdot \mathrm{s} \cdot \mathrm{ml}^{-1}$ and $\tau=0.30 \mathrm{~g} \cdot \mathrm{s} \cdot \mathrm{ml}^{-1}$ in propane oxidation at $\mathrm{T}=673 \mathrm{~K}$ over M1 MoVTeNb oxide (catalyst ID 6059) in the feed $\mathrm{C}_{3} \mathrm{H}_{8} / \mathrm{O}_{2} / \mathrm{H}_{2} \mathrm{O} / \mathrm{N}_{2}=3 / 6 / \mathrm{x} /$ balance vol.- $\%$, $\mathrm{x}=0$ (open symbols), 40 (filled symbols).

The impact of steam on the concentration of propane and reaction products in the feed is summarized in Figure 7. Propane oxidation was carried out at $673 \mathrm{~K}$ applying various short contact times and different steam content in the feed between 0 and 40 vol.- $\%$ in steps of 10 vol.- $\%$. The results are exemplarily shown for dry feed (open symbols for products) and 40 vol.- $\%$ steam in the feed (filled symbols for products). The conversion of propane increases with increasing contact times and is slightly enhanced by the presence of steam. In dry feed, the concentration of acrylic acid sharply drops in favour of total combustion to carbon oxides so that almost no acrylic acid is formed without feeding steam. At the very short contact times applied, propylene concentration is barely affected by steam. Cyclic experiments between dry and wet feed have been performed revealing that the product distribution is reversibly restored by returning to the original reaction conditions.

\subsection{In-situ photoelectron spectroscopy}

Fig. 8 shows the evolution of acrylic acid abundance during the high-pressure in-situ XPS experiments as determined by online PTR-MS (m/e=72 amu). First, the catalyst has been heated stepwise to 513 and $693 \mathrm{~K}$ in a flow of oxygen, propane and $\mathrm{He}$ at a total pressure of $25 \mathrm{~Pa}$. The horizontal bars marked with letters A-J indicate time spans when sets of XPS core level spectra have been recorded. After approximately $10 \mathrm{~h}$ of $\mathrm{O}_{2} / \mathrm{C}_{3} \mathrm{H}_{8} / \mathrm{He}$ stream the $\mathrm{He}$ gas flow has been replaced by $\mathrm{H}_{2} \mathrm{O}$ vapour as indicated by the vertical dashed line. While heating in $\mathrm{H}_{2} \mathrm{O}$-free reaction feed caused only a small transient evolution in acrylic acid abundance the adding of water vapour results in an immediate strong increase of the acrylic acid production. With time on stream the acrylic acid signal increases steadily and 


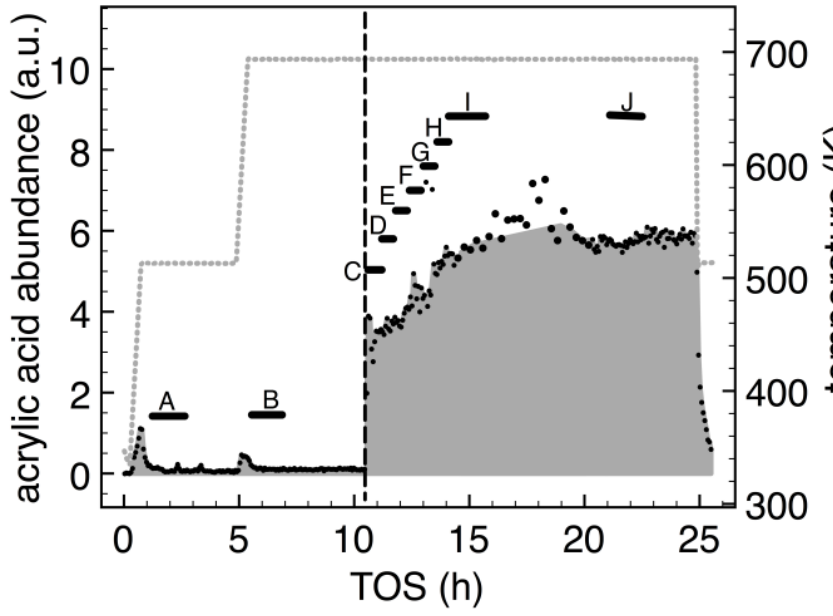

Figure 8. Evolution of acrylic acid abundance (black data points) with time on stream (TOS) during the in-situ XPS measurements when the temperature was increased stepwise from $323 \mathrm{~K}$ to $513 \mathrm{~K}$ and finally to $693 \mathrm{~K}$. The temperature program is shown as dotted gray line. The horizontal bars marked A-J define time spans when XPS spectra have been recorded. After approximately $10 \mathrm{~h}$ TOS in dry feed $\left(\mathrm{C}_{3} \mathrm{H}_{8} / \mathrm{O}_{2} / \mathrm{He}=2 / 1 / 2.8 \mathrm{sccm}\right.$ (measurements $\mathrm{A}$ and $\mathrm{B}$ )), steam has been added $\left(\mathrm{C}_{3} \mathrm{H}_{8} / \mathrm{O}_{2} / \mathrm{H}_{2} \mathrm{O}_{(\mathrm{g})}=2 / 1 / 2.8 \mathrm{sccm}\right.$ (measurements C-J)). The switch from dry to wet feed is indicated by the dashed vertical line.

finally levels off after $5 \mathrm{~h}$. The acrylic acid performance of the sample remained constant for the rest of the experiment $(10 \mathrm{~h})$. These data show directly that the catalytic performance of the catalyst is qualitatively similar during the XPS experiments and the reactor studies at atmospheric pressure (Fig. 7). The material shows a constant production of acrylic acid in the XPS cell, but only after the addition of steam. Thus, one can safely assume that the XPS data taken during the reaction show the relevant active surface state. The small transient signal of acrylic acid when heated to $513 \mathrm{~K}$ and $693 \mathrm{~K}$ in a reaction feed without steam suggests a reaction with pre-formed active centres on the surface. Since these centres cannot be re-created due to the missing steam in the reactant gas, no steady production of acrylic acid is observed. Side products have been observed by online PTR-MS in the absence of steam in the feed that presumably can be assigned to acetic acid, acetone, acrolein and acetaldehyde (data not shown) giving a hint to further side reactions. The observations point to a critical role of water in restoring the active sites.

The elemental metal surface composition as obtained by XPS is presented in Fig. 9 together with the acrylic acid evolution. The experiment index indicates the time span when the data have been obtained in the course of the reaction as shown in Fig. 8. The elemental composition determined by EDX before the reaction is also shown. All abundance data have been normalised to the Mo content.

The surface composition of phase pure M1 deviates from the bulk composition as determined by EDX (Table 1) in agreement with previous studies.[29] At $513 \mathrm{~K}$ in $\mathrm{O}_{2} / \mathrm{C}_{3} \mathrm{H}_{8} / \mathrm{He}$ the surface exhibits a slight excess in Te while mainly the $\mathrm{V}$ content and, to a minor degree, $\mathrm{Nb}$ was reduced compared to the bulk composition. Heating to the reaction temperature of $693 \mathrm{~K}$ in the absence of steam caused a slight decrease in the $\mathrm{Te}, \mathrm{Nb}, \mathrm{V}$ abundance on the surface, i.e. the surface got even more enriched in Mo. Actually, the metal abundance found in steam free atmosphere $(\mathrm{Mo} / \mathrm{V} / \mathrm{Te} / \mathrm{Nb}: 0.71 / 0.08 / 0.10 / 0.10)$ is close to the ratio given for $\mathrm{M} 1(\mathrm{Mo} / \mathrm{V} / \mathrm{Te} / \mathrm{Nb}: 0.71 / 0.11 / 0.09 / 0.09)$ e.g. by [11] except for a reduced $\mathrm{V}$ content. It is noted that this surface is barely active in selective oxidation.

Adding steam to the feed changed the surface composition immediately. $\mathrm{Te}, \mathrm{V}, \mathrm{Nb}$ got enriched on the surface and consequently the Mo abundance decreased. The impact of steam is strongest for Te and $\mathrm{V}$ and slightly less pronounced for $\mathrm{Nb}$. The trend of surface modification continued steadily with time on stream although the rate of surface enrichment of these elements slowed down. Interestingly, the $\mathrm{Te} / \mathrm{V}$ element ratio remains remarkably constant after adding steam to the feed $(\mathrm{Te} / \mathrm{V}=1.4)$ while there is a slight increase in the $\mathrm{Te} / \mathrm{Nb}$ ratio with time on stream, especially when considering the data after long time on stream (approx. $22 \mathrm{~h}$ total TOS).

The binding energy (BE) of $\mathrm{Mo}_{5 / 2}(232.5 \pm 0.1 \mathrm{eV})$ is close to the value of $232.6 \mathrm{eV}$ typically reported for $\mathrm{MoO}_{3}$ $[25,29,53-55]$. This suggests a single Mo valence of +6 with an upper limit of $5 \%$ for a contribution of $\mathrm{Mo}^{5+}$ in agreement to previous studies of phase-pure M1 [29]. A BE of $206.8 \pm 0.1 \mathrm{eV}$ was found for $\mathrm{Nb} \mathrm{d}_{5 / 2}$ suggesting a $\mathrm{Nb}$ valence of +5 , while the $\mathrm{BE}$ of $\mathrm{Te} 3 \mathrm{~d}_{5 / 2}$ was determined to $576.4 \pm 0.1 \mathrm{eV}$, within the range of $\mathrm{BE}$ reported for $\mathrm{TeO}_{2}$ $(576.1-576.5 \mathrm{eV})$, i.e. $\mathrm{Te}^{4+} .[56]$ No formation of $\mathrm{Te}^{0}(\mathrm{BE}$ $573 \mathrm{eV}$ ) was observed during the measuring process that allows ruling out a significant damage of the surface structure due to reduction by the brilliant synchrotron X-ray

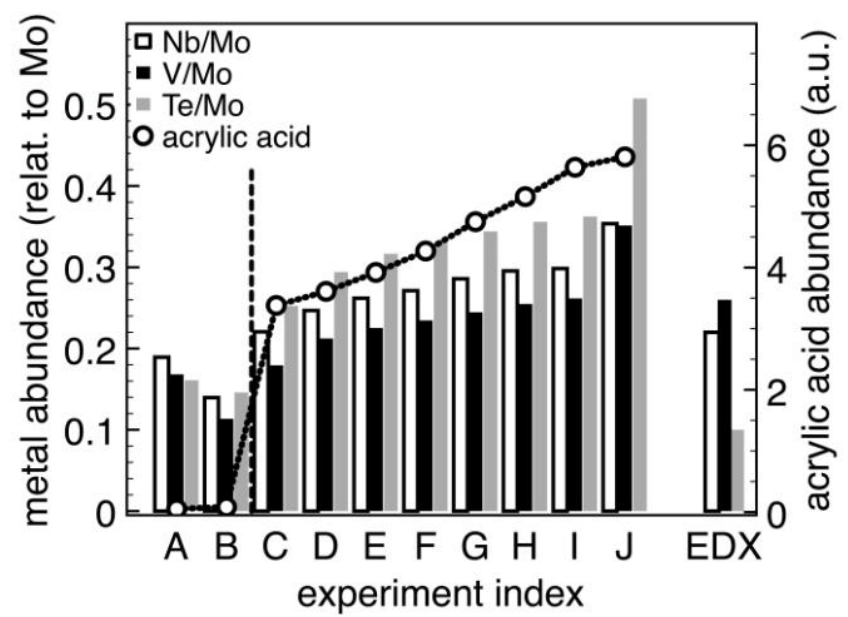

Figure 9. The elemental metal surface composition as determined by XPS is compared with the simultaneously recorded acrylic acid abundance. Reaction conditions / experiment index is given in Fig. 8. The bulk composition as obtained by EDX before the reaction is also shown for comparison. 

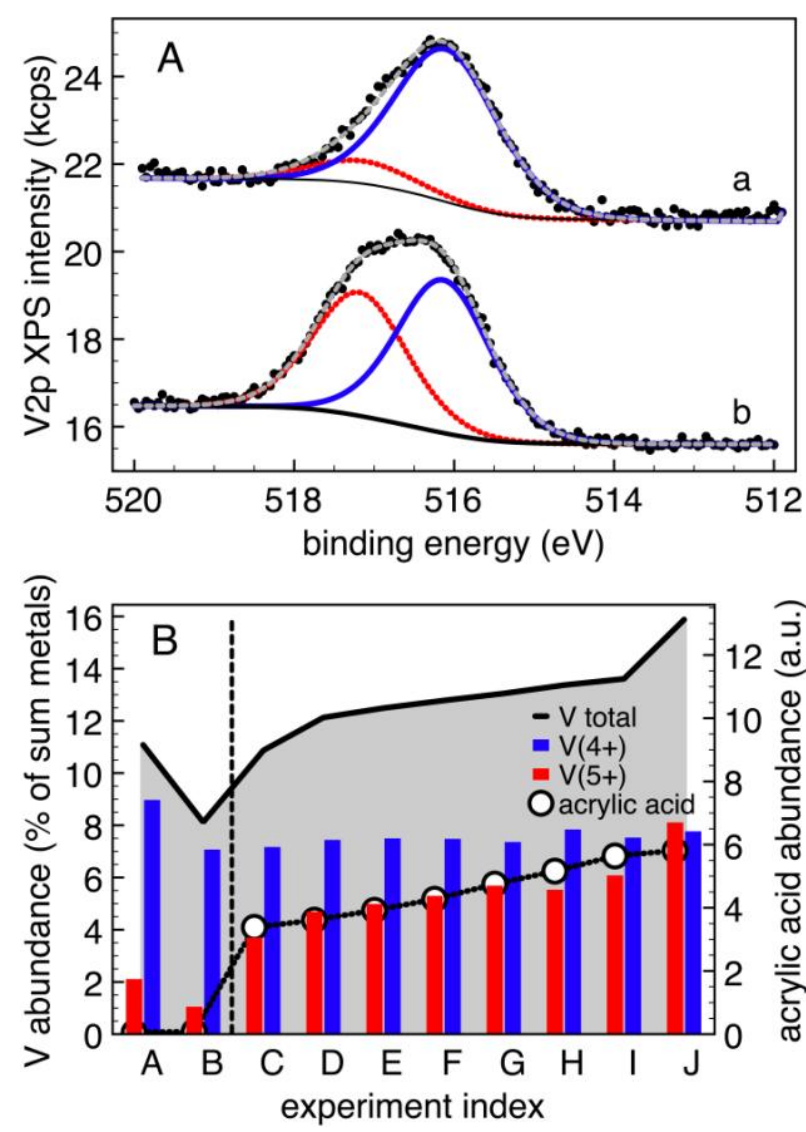

Figure 10. A. De-convolution of the V2 $\mathrm{p}_{3 / 2}$ core level spectra: Two components representing $\mathrm{V}^{4+}$ (blue line) and $\mathrm{V}^{5+}$ (red line) species have been used. The sum curve obtained by the fit (dashed gray line) is compared with the data points (black dots) The XP spectra have been obtained using an excitation energy of $650 \mathrm{eV}$ at $693 \mathrm{~K}$ a) without and b) with steam added to the feed. In B. the V total abundance (solid black line) and the evolution of $\mathrm{V}^{4+}$ (blue bars) and $\mathrm{V}^{5+}$ (red bars) species is compared with the simultaneously determined acrylic acid abundance. Reaction conditions / TOS as indicated by the experiment index (compare to Fig. 8).

beam. In previous studies, surface decomposition accompanied by liberation of Te was observed already at ambient temperature when the catalysts was no single-phase M1, but a phase mixtures, and when the sample was exposed to $\mathrm{X}$-rays in vacuum. In the present investigation, phase-pure M1 was used and spectra were measured exclusively in presence of gas phase resulting in stable and reproducible results without spatial gradients. No modification of the spectral shape could be observed neither in the Te3d, Nb3d nor Mo3d core levels during reaction (data not shown) indicating that these elements occur in their as-prepared valence during catalytic actions. In contrast to this, the V2p core level peak broadened due to an increased intensity at the high $\mathrm{BE}$ side after the addition of steam to the feed. A de-convolution of the $\mathrm{V} 2 \mathrm{p}_{3 / 2}$ revealed the presence of two components with a $\mathrm{BE}$ difference of $1.05 \mathrm{eV}$ resulting in a $\mathrm{BE}$ around $516.1 \pm 0.1 \mathrm{eV}$ and $517.2 \pm 0.1 \mathrm{eV}$ as demonstrated in Fig. $10 \mathrm{~A}$ that can be assigned to $\mathrm{V}^{4+}$ and $\mathrm{V}^{5+}$ species[25, 29, 53, 57]. Remarkably, the $\mathrm{V}^{5+}$ and $\mathrm{V}^{4+}$ com- ponent seems to possess a similar full width half maximum (FWHM) of $1.3 \pm 0.1 \mathrm{eV}$ in contrast to the rather large FWHM typically observed for binary $\mathrm{V}^{4+}$ oxides of about 2-3 eV.[28, 57] This suggests that no strong geometric relaxation is associated with the valence change. Fig. $10 \mathrm{~B}$ shows the total vanadium abundance, and the distribution of $\mathrm{V}^{4+}$ and $\mathrm{V}^{5+}$ species, respectively, as obtained by a consistent, constraint fit of $\mathrm{V} 2 \mathrm{p}_{3 / 2}$ core level spectra taken at different TOS (for experiment index compare to Fig. 8) using the peak model outlined above and the evolution of the acrylic acid abundance. While there were almost no $\mathrm{V}^{5+}$ species present in the absence of steam at $513 \mathrm{~K}$ and $693 \mathrm{~K}$, a steady build up of $\mathrm{V}^{5+}$ species was observed after $\mathrm{H}_{2} \mathrm{O}$ vapour has been added to the feed resulting in a $\mathrm{V}^{4+}$ to $\mathrm{V}^{5+}$ ratio close to 1 after prolonged time on stream. The $\mathrm{V}^{4+}$ species abundance remains rather constant in steam after the decrease when the catalyst has been heated from $513 \mathrm{~K}$ to $693 \mathrm{~K}$ in $\mathrm{O}_{2} / \mathrm{C}_{3} \mathrm{H}_{8} / \mathrm{He}$.

To study the impact of the element composition and $\mathrm{V}$ oxidation state on the functionality of the surface, the evolution of the Mo and $\mathrm{V}^{5+}$ species abundance is plotted versus the acrylic acid abundance in Fig. 11. Data representing the inactive catalyst (experiment $\mathrm{A}$ at $513 \mathrm{~K}$ ) and under reaction conditions while the catalyst approaches a stationary state (experiment C-I, $693 \mathrm{~K}$ with steam) are included. Obviously, the increasing formation of acrylic acid in general goes along with the trend of a surface depletion or coverage of Mo and accordingly the enrichment in $\mathrm{Te} / \mathrm{V} / \mathrm{Nb}$. Furthermore, a close correlation between the acrylic acid abundance and the increasing presence of $\mathrm{V}^{5+}$ species on the surface could be revealed. Strikingly, the data point at about 3.5 units acrylic acid abundance (experiment $\mathrm{C}$ ) shows the largest deviation from a suggested linear relationship for both the depletion with Mo and creation of $\mathrm{V}^{5+}$ centres on the surface. It can be speculated that this effect might be related to the treatment of the

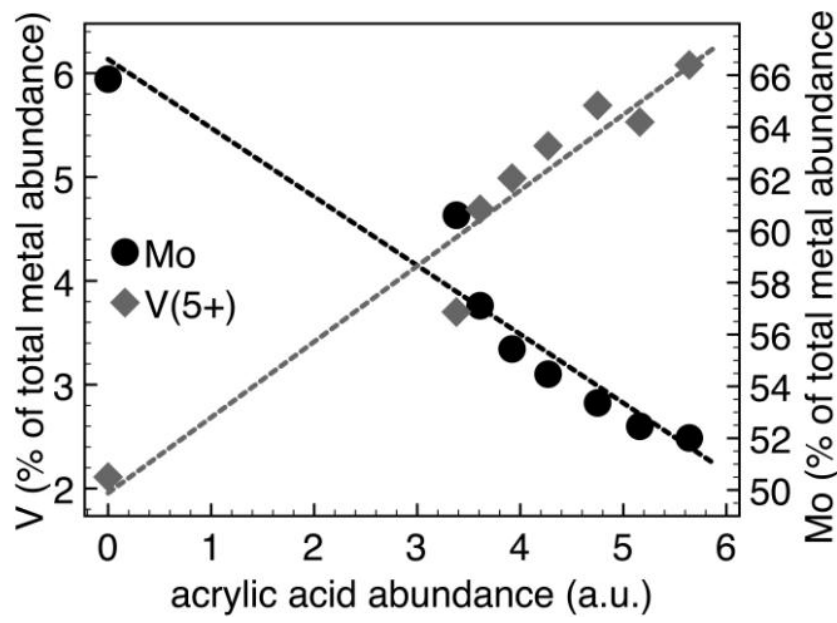

Figure 11. Relationship between the acrylic acid abundance and the surface element content of $\mathrm{V}^{5+}$ species (gray squares) and Mo (black dots). Dashed lines included as guide to the eyes. 

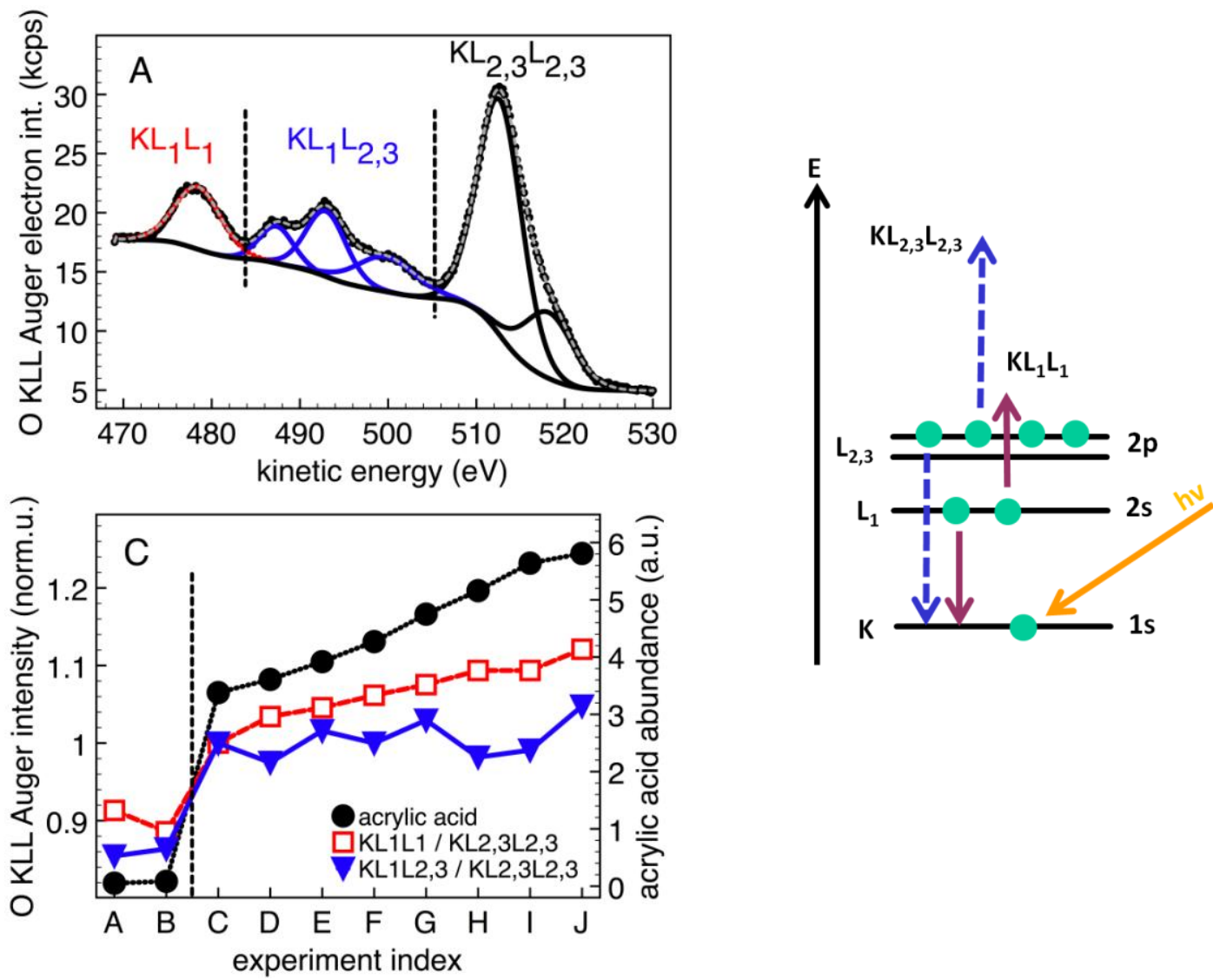

Figure 12. In A. a characteristic X-ray induced O KLL Auger electron spectrum under reaction conditions $\left(\mathrm{C}_{3} \mathrm{H}_{8} / \mathrm{O}_{2} / \mathrm{H}_{2} \mathrm{O}_{(\mathrm{g})}\right.$ feed at $\left.693 \mathrm{~K}\right)$ is depicted. The photon energy was $650 \mathrm{eV}$. Regions assigned to different electronic transitions are indicated by dashed lines. A simplified term scheme is shown in B, and the intensity ratio of different O KLL Auger electron transitions is compared with the simultaneously determined acrylic acid abundance in $\mathrm{C}$. The experiment index refers to Fig. 8. Further details are explained in the text.

catalysts at $693 \mathrm{~K}$ without steam in the feed (experiment B) that might have disrupted the active surface state.

The analysis of the XPS core level spectra revealed a modification of the elemental composition of the surface and a partial oxidation of $\mathrm{V}$ centres. X-ray induced oxygen Auger electron spectra have been used to gather some information how this might have affected the electronic structure of oxygen atoms that connect the metal centres. Typically, the O1s core level spectra of d-block metal oxides are not very sensitive to small modification of the connectivity since the "chemical shift" is rather small and $\mathrm{O} 1 \mathrm{~s}$ spectra cannot be resolved. [28] Fig. 12 A presents a characteristic O KLL-Auger electron spectrum obtained at 693 $\mathrm{K}$ in the reaction mixture with steam added to the feed. In general, the features of the O KLL-Auger electron spectrum can be grouped into 3 regions that can be assigned to different transitions of the participating electrons in the Auger process.[58] A simple term scheme explaining the details is shown as Fig. 12 B. Briefly, after an 1s electron is removed by X-ray excitation the hole in the $1 \mathrm{~s}$ shell is either filled by an electron from the $\mathrm{L}_{1}(2 \mathrm{~s})$ or $\mathrm{L}_{2,3}(2 \mathrm{p})$ shell accompanied by a release of an Auger electron into vacuum from the corresponding shell. These Auger electrons carry different kinetic energy related to the binding energy of the core level. There can be different contributions of oxygen atoms e.g. with a different bonding configuration within each region assigned to transitions outlined above. Further effects like inter-atomic processes are neglected in this simple intra-atomic view.

According to the model introduced by Weißmann, variation of the intensity I of these three regions specific to certain transitions can be related to the average partial charge $\Delta$ qe that is added or removed from the oxygen site when the chemical bond is formed/modified [59]:

$\mathrm{I}\left(\mathrm{KL}_{1} \mathrm{~L}_{1}\right) \sim \mathrm{q}\left(\mathrm{L}_{1}\right)\left[\mathrm{q}\left(\mathrm{L}_{1}\right)-1\right] \mathrm{M}\left(\mathrm{L}_{1} \mathrm{~L}_{1}\right)$

$\mathrm{I}\left(\mathrm{KL}_{1} \mathrm{~L}_{2,3}\right) \sim \mathrm{q}\left(\mathrm{L}_{1}\right) \mathrm{q}\left(\mathrm{L}_{2,3}\right) \mathrm{M}\left(\mathrm{L}_{1} \mathrm{~L}_{2,3}\right)$

$\mathrm{I}\left(\mathrm{KL}_{2,3} \mathrm{~L}_{2,3}\right) \sim \mathrm{q}\left(\mathrm{L}_{2,3}\right)\left[\mathrm{q}\left(\mathrm{L}_{2,3}\right)-1\right] \mathrm{M}\left(\mathrm{L}_{2,3} \mathrm{~L}_{2,3}\right)$

with $\mathrm{q}=\mathrm{q}_{0}+\Delta \mathrm{qe}$, e.g. $\mathrm{q}=4 \mathrm{e}+\Delta \mathrm{qe}$ when the $\mathrm{L}_{2,3}$ shell is associated with the bond (4e is the electron charge of the neutral atom). $\mathrm{M}$ is the Auger electron transition probability of the indicated transition. Thus, the intensity ratio (i.e. $\mathrm{I}\left(\mathrm{KL}_{1} \mathrm{~L}_{1}\right) / \mathrm{I}\left(\mathrm{KL}_{2,3} \mathrm{~L}_{2,3}\right)$ and $\mathrm{I}\left(\mathrm{KL}_{1} \mathrm{~L}_{2,3}\right) / \mathrm{I}\left(\mathrm{KL}_{2,3} \mathrm{~L}_{2,3}\right)$ ) of the Auger electron transitions is proportional to the charge transferred $\Delta$ qe due to the bond associated with the $\mathrm{L}_{2,3}$ 
shell under the assumption that the Auger electron transition probability ratio (e.g. $\left.\mathrm{M}\left(\mathrm{KL}_{1} \mathrm{~L}_{1}\right) / \mathrm{M}\left(\mathrm{KL}_{1} \mathrm{~L}_{2,3}\right)\right)$ is independent of the chemical bond. For details refer to the original paper of Weißmann. [59]

This model has been applied successfully to analyse the different oxygen ionicity (e.g. Pauling charge or orbital population) of binary metal oxides.[59-61]. The application to a complex mixed oxide like $\mathrm{MoVTeNbO}_{\mathrm{x}}$ gives much less detailed information but the general character of the oxygen sites are probably revealed. Fig. $12 \mathrm{C}$ presents the intensity variation of the $\mathrm{KL}_{1} \mathrm{~L}_{1}$ and $\mathrm{KL}_{1} \mathrm{~L}_{2,3}$ region relative to the $\mathrm{KL}_{2,3} \mathrm{~L}_{2,3}$ region in the $\mathrm{O}$ Auger spectra in the course of the reaction. One observes a relative intensity increase after steam has been added to the feed. In the Weißmann model this can be interpreted as a removal of partial charge $\Delta$ qe (per oxygen atom) from the oxygen atom, i.e., the bond gets less ionic. An increase of the covalent character of the $\mathrm{V}-\mathrm{O}$ bond with increasing formal oxidation state has been reported for $e . g$. binary vanadium oxides. [57]

\section{Discussion}

The oxidation of propane proceeds with high selectivity to the desired partial oxidation products propylene and acrylic acid over MoVTeNb oxide composed exclusively of the M1 phase. The well-defined and stable bulk structure of this phase provides an appropriate basis for studying surface dynamics necessarily associated with catalysis of redox reactions. Selective transformation of propane to acrylic acid involves the abstraction of four hydrogen atoms, the insertion of two oxygen atoms and the transfer of eight electrons. Selectivity in the underlying multi-step reaction network is determined by the relative abundance of surface intermediates such as alkoxides, Oallyl, and carboxylate species, which is controlled by the balance of redox and acid-base properties of the catalyst and by the reaction conditions. FTIR of adsorbed ammonia shows that the surface of an activated, crystalline MoV$\mathrm{TeNb}$ oxide catalyst consisting exclusively of the M1 phase is characterized by moderate acidity with respect to concentration and strength of sites, which are predominantly of Brønsted-type. New hydroxyl groups are introduced by implementation of tellurium into the ternary $\mathrm{MoV}$ oxide. Formation of $\mathrm{Te}-\mathrm{OH}$ groups requires the disruption of the $(\mathrm{TeO})_{\mathrm{n}}$ zigzag chains in the hexagonal channels and may result from hydroxylation of these chains exposed in the opened channels on the lateral termination of the M1 needles. The overall acidity of MoV oxide is not very different from the acidity of MoVTeNb oxide, suggesting that the low selectivity towards acrylic acid that has been observed for ternary MoV catalysts is not necessarily related to differences in the acid-base properties.[4]

The activation of propane for hydrogen abstraction will happen at terminating oxygen species.[1, 62] The most striking surface property of the activated M1 phase consists in its high number of energetically homogeneous propane adsorption sites as revealed by microcalorimetry. In this respect, the quinternary oxide is clearly different compared to the binary and ternary reference oxides, which show with the exception of tellurium oxide generally low heats of adsorption of propane. Besides, all reference oxides have a high diversity of energetically different adsorption sites. The monolayer capacity of the particular M1 catalyst studied in the present work comprises approximately $\mathrm{N}_{\text {mono }}=43$ $\mu \mathrm{mol}_{\text {propane }} \cdot \mathrm{g}_{\text {cat }}{ }^{-1}$ as derived from adsorption isotherm of propane measured at $313 \mathrm{~K}$. This numerical value may allow some reflections about the abundance of active sites on the M1 surface. The maximum space-time yield (STY) achieved under the reaction conditions applied in the present study with the same M1 catalyst accounts for $\mathrm{STY}=0.58 \mathrm{mmol}_{\text {acrylic acid }} \mathrm{g}_{\text {cat }}{ }^{-1} \mathrm{~h}^{-1}$. Assuming that all propane adsorption sites correspond to active sites, a quite low turnover number results that accounts for approximately $0.01 \mathrm{~s}^{-1}$, which increases to $1 \mathrm{~s}^{-1}$ if only $1 \%$ of the propane adsorption sites are taken into account. One complete formula conversion then proceeds in about $1 \mathrm{~s}$, which is comparatively slowly compared to heterogeneously catalyzed oxidation reactions that generally require $10^{-2} \mathrm{~s},[63]$ which again implies that only $0.01 \%$ of the adsorption sites could be active sites.

Since the reflections made above are based on the comparison of steady state productivity observed at $673 \mathrm{~K}$ in the feed of reactants and the number of propane adsorption sites measured by microcalorimetry at room temperature, the resulting picture might reflect just a rough idea, in particular, because microcalorimetry of adsorbed propane reveals that the catalyst surface is considerably changed after testing the catalyst in a fixed bed reactor probing surface sites that adsorb propane less strongly. This illustrates the necessity of catalyst characterization under working conditions. High-pressure photoelectron spectroscopy performed under conditions at which the catalyst is producing acrylic acid clearly shows that the M1 surface is so different from the bulk that the M1 structure cannot be realized with the experimentally determined cation distribution. Moreover, elemental composition and oxidation state of vanadium vary with the reaction conditions and these alterations go along with changes in the selectivity towards acrylic acid. The surface of the active catalysts is enriched in $\mathrm{Te} / \mathrm{V} / \mathrm{Nb}$ and depleted in Mo and thus different to the M1 bulk composition, which is in agreement with a termination model based on STEM.[23] The differences between surface and bulk composition of M1 probed by integral surface sensitive methods can be in particular ascribed to the specific termination of the M1 crystals along the lateral surface of the needle or rod-like particles. The perimeter of the lateral M1 surface seems to be created along directions with minimum number of bonds to be broken. Building such a termination is shown exemplarily in Schema 1 that represents a two-dimensional projection of the polyhedral network in the crystallographic (001) plane (basal plane of M1). Among the many nearest neighbor lines, a continuous pathway has been chosen arbitrarily. The exact fracture line may vary and may depend on the metal site occupancy, which, in turn, is controlled by the chemical composition of 


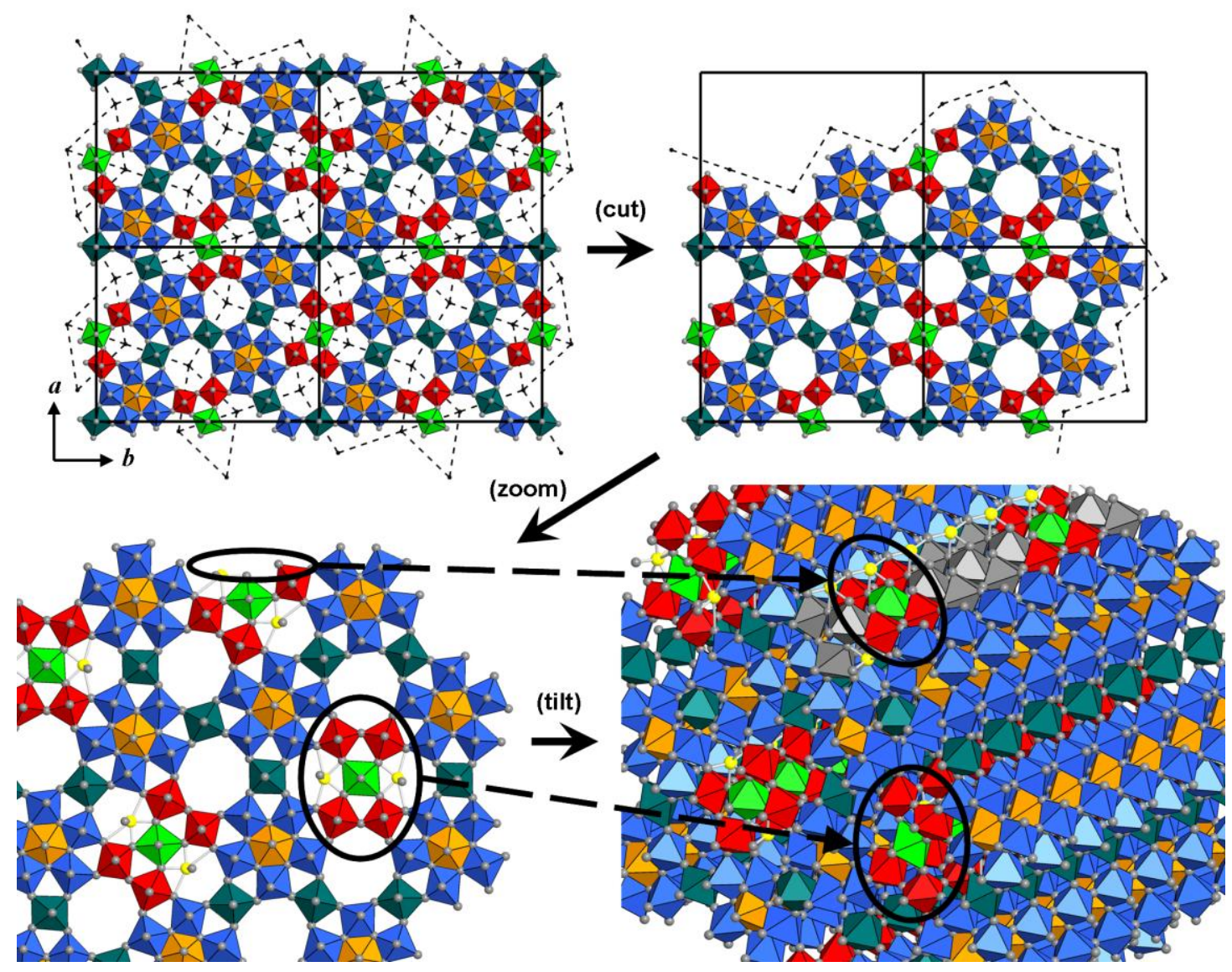

Scheme 1. Termination model of the M1 phase

the synthesis gel and the synthesis kinetics. In any case, the lateral surface of the cylindrical M1 particles is constituted of roughly half-pipes from the formerly closed channels and from wall fragments exposing now the inner surface of the channels. These "rain pipes" filled with tellurium oxospecies run probably along the whole prismatic faces as indicated by the stepped surface morphology. Consequently, lateral termination, in particular, liberates tellurium oxo-groups that are no longer contained in the channels but can disperse over the whole surface. Such a termination of M1 explains the excess in Te detected at the surface by XPS in high-vacuum [4, 16, 25-27] and highpressure experiments,[29] and the observation of surface Te-OH groups by infrared spectroscopy. Furthermore, the proposed termination mechanism provides an explanation for the experimental observation that reactive sites, such as indicated by ellipsoids in Schema 1 on the $a b$ plane and on the lateral surface, exist on all orientations of the anisotropic faces of the M1 crystals.[20]

The concentration of steam in the feed has, in agreement with the experiments in the fixed bed reactor, the strongest impact on acrylic acid formation in the high pressure XPS experiment. Essentially, steam in the feed causes i) depletion or coverage of molybdenum on the catalyst surface and ii) increase in the average oxidation state of vanadium. The correlation between acrylic acid productiv- ity and formation of $\mathrm{V}^{5+}$ oxo-centres on the surface corroborate the view of $\mathrm{V}^{5+}$ sites as part of the catalytic sites for propane activation.[14] Under dry feed conditions when propylene is predominantly formed, the surface concentration of $\mathrm{V}^{5+}$ sites is quite low, possibly implying that isolated $\mathrm{V}^{5+}$ oxo-species accomplish oxidative dehydrogenation of propane to propylene over M1. The relative increase in the concentration of $\mathrm{V}^{5+}$ species and possible association of $\mathrm{V}^{5+}$ surface sites by re-structuring of the surface in wet feed may enable acrylic acid formation. The quite constant $\mathrm{Te} / \mathrm{V}$ ratio suggests active ensembles with $\mathrm{V}$ and $\mathrm{Te}$ in close proximity as suggested previously.[14, 29] The oxygen-metal bond in the active centres might have more covalent character in presence than in the absence of steam. The observed dynamics require surface re-structuring and solid-state transport under reaction conditions that seems to be facilitated by hydrolysis of surface metal-oxygen bonds in the presence of steam without disrupting the entire bulk structure. The exceptional stability of the catalyst might be associated with the open, bronze-like crystal structure of the M1 phase. Whether these structural changes are fully reversible remains an open question that will be tackled in the future by in-situ XPS experiments in which the feed composition is varied systematically. Furthermore, notwithstanding the qualitative agreement between the catalytic results in the 
XPS chamber and in the fixed bed reactor, the gap between the different total pressures in the two experiments and unequal flow conditions due to the usage of a thin pressed wafer in in-situ XPS possibly have implications on the catalyst surface and the reaction mechanism of propane oxidation. Currently, the pressure dependency of propane oxidation applying X-ray absorption spectroscopy and as far as possible XPS is under investigation in a wide range of total pressures.

\section{Conclusions}

Based on in-situ investigations of an activated highly crystalline, phase-pure M1 MoVTeNb oxide catalyst before catalysis and under working conditions of propane oxidation to acrylic acid the following model of the active catalyst surface is proposed:

1. The catalytic properties of the M1 phase of MoVTeNb oxide seems to be controlled by the redox chemistry of the solid, because the acidity, which mainly comprises Brønsted acid sites, is comparatively weak, but, probably contributes to the disruption of C-C bonds and formation of undesired by-products.

2. The surface of the activated M1 phase at $313 \mathrm{~K}$ is characterized by a high number of energetically homogeneous sites for propane adsorption. The differential heat of adsorption indicates a strong interaction of propane with the M1 surface that is, however, reduced after catalysis suggesting that substantial changes of the surface properties occur under reaction conditions.

3. These changes have been analyzed while the catalyst was working by high-pressure in-situ XPS. The experiment confirms that the surface composition of M1 differs significantly from the bulk implying that the active sites on the surface are no part of the M1 crystal structure. Exposure of the inner surface of the hexago- nal and heptagonal channels on the lateral termination of the rod shaped M1 particles provides a comprehensible explanation for the differences in chemical composition and the existence of potential active ensembles on the entire M1 surface.

4. Acrylic acid formation correlates with the depletion of the catalyst surface in $\mathrm{Mo}^{6+}$ and the enrichment of the surface with $\mathrm{V}^{5+}$ sites. Dynamic changes of the metal valence states under reaction conditions are restricted to vanadium. Therefore, the M1 phase is understood as a structurally stable carrier that enables the formation of a thin active surface layer that contains $\mathrm{V}^{5+}$ in close vicinity to $\mathrm{Te}^{4+}$ oxo-sites. The chemical composition of the layer and the $\mathrm{V}$ oxidation state on the surface respond to the water content in the feed, which is reflected in the product distribution in propane oxidation.

\section{Acknowledgements}

The authors thank G. Lorenz and D. Brennecke for their help with the $\mathrm{N}_{2}$ physisorption measurements, and Dr. G. Auffermann (MPI for Chemical Physics of Solids, Dresden, Germany) for chemical analysis. We thank Dr. Alexander Yu. Stakheev for stimulating discussions at the Second Geman-Russian Seminar on Catalysis, Kloster Seeon, March 2010. The HZB staff is acknowledged for their continual support of the high pressure electron spectroscopy activities of the FHI at BESSY II. This work was partially supported by the German Research Foundation (Deutsche Forschungsgemeinschaft, DFG) through the cooperate research center "Structure, dynamics, and reactivity of transition metal oxide aggregates" (Sonderforschungsbereich 546, http://www.chemie.huberlin.de/sfb546).

\section{References}

[1] X. Rozanska, R. Fortrie, J. Sauer, The Journal of Physical Chemistry C, 111 (2007) 6041.

[2] R.K. Grasselli, J.D. Burrington, D.J. Buttrey, P. De Santo, Jr., C.G. Lugmair, A.F. Volpe, Jr., T. Weingand, Topics in Catalysis, 23 (2003) 5.

[3] P. Botella, J.M. Lopez Nieto, B. Solsona, A. Mifsud, F. Marquez, Journal of Catalysis, 209 (2002) 445.

[4] W. Ueda, D. Vitry, T. Katou, Catalysis Today, 96 (2004) 235.

[5] P. Botella, E. Garcia-Gonzalez, A. Dejoz, J.M. Lopez Nieto, M.I. Vazquez, J. Gonzalez-Calbet, Journal of Catalysis, 225 (2004) 428.

[6] T. Katou, D. Vitry, W. Ueda, Catalysis Today, 91-92 (2004) 237.

[7] L. Yuan, V.V. Guliants, M.A. Banares, S.J. Khatib, Topics in Catalysis, 49 (2008) 268.

[8] B. Solsona, F. Ivars, P. Concepcion, J.M. Lopez Nieto, Journal of Catalysis, 250 (2007) 128.

[9] F. Wang, W. Ueda, Applied Catalysis, A: General, 346 (2008) 155.

[10] M. Aouine, J.M.M. Millet, J.L. Dubois, Chemical Communications, (2001) 1180.

[11] P. DeSanto, Jr., D.J. Buttrey, R.K. Grasselli, C.G. Lugmair, A.F. Volpe, Jr., B.H. Toby, T. Vogt, Zeitschrift fuer Kristallographie, 219 (2004) 152.

[12] H. Murayama, D. Vitry, W. Ueda, G. Fuchs, M. Anne, J.L. Dubois, Applied Catalysis, A: General, 318 (2007) 137.

[13] A. Müller, P. Kogerler, C. Kuhlmann, Chemical Communications, (1999) 1347.

[14] R.K. Grasselli, D.J. Buttrey, P. DeSanto, J.D. Burrington, C.G. Lugmair, A.F. Volpe, Jr., T. Weingand, Catalysis Today, 91-92 (2004) 251.

[15] K. Oshihara, T. Hisano, W. Ueda, Topics in Catalysis, 15 (2001) 153 
[16] J.M.M. Millet, H. Roussel, A. Pigamo, J.L. Dubois, J.C. Jumas, Applied Catalysis, A: General, 232 (2002) 77.

[17] J.-M.M. Millet, Topics in Catalysis, 38 (2006) 83.

[18] R.K. Grasselli, Catalysis Today, 99 (2005) 23.

[19] R.K. Grasselli, D.J. Buttrey, J.D. Burrington, A. Andersson, J. Holmberg, W. Ueda, J. Kubo, C.G. Lugmair, A.F. Volpe, Jr., Topics in Catalysis, 38 (2006) 7.

[20] A. Celaya Sanfiz, T.W. Hansen, A. Sakthivel, A. Trunschke, R. Schlögl, A. Knoester, H.H. Brongersma, M.H. Looi, S.B.A. Hamid, Journal of Catalysis, 258 (2008) 35.

[21] V.V. Guliants, R. Bhandari, H.H. Brongersma, A. Knoester, A.M. Gaffney, S. Han, Journal of Physical Chemistry B, 109 (2005) 10234

[22] N.R. Shiju, X. Liang, A.W. Weimer, C. Liang, S. Dai, V.V. Guliants, Journal of the American Chemical Society, 130 (2008) 5850.

[23] W. Zhang, A. Trunschke, R. Schlögl, D. Su, Angewandte Chemie International Edition, 49 (2010) 6084.

[24] M. Baca, A. Pigamo, J.L. Dubois, J.M.M. Millet, Topics in Catalysis, 23 (2003) 39.

[25] M. Baca, J.-M.M. Millet, Applied Catalysis A: General, 279 (2005) 67.

[26] P. Botella, P. Concepcion, J.M.L. Nieto, Y. Moreno, Catalysis Today, 99 (2005) 51.

[27] F. Ivars, P. Botella, A. Dejoz, J.M.L. Nieto, P. Concepcion, M.I. Vazquez, Topics in Catalysis, 38 (2006) 59.

[28] D. Teschner, E.M. Vass, R. Schlögl, Photoelectron Spectroscopy of Catalytic Oxide Materials, in: S.D. Jackson, J.S.J. Hargreaves (Eds.) Metal Oxide Catalysis, Wiley-VCH: Weinheim, 2009, pp. 243.

[29] A. Celaya Sanfiz, T.W. Hansen, D. Teschner, P. Schnörch, F. Girgsdies, A. Trunschke, R. Schlögl, M.H. Looi, S.B.A. Hamid, The Journal of Physical Chemistry C, 114 (2010) 1912.

[30] W.D. Pyrz, D.A. Blom, N.R. Shiju, V.V. Guliants, T. Vogt, D.J. Buttrey, J. Phys. Chem. C, 112 (2008) 10043.

[31] B. Deniau, G. Bergeret, B. Jouguet, J.L. Dubois, J.M.M. Millet, Topics in Catalysis, 50 (2008) 33.

[32] L.C. Jozefowicz, H.G. Karge, E.N. Coker, The Journal of Physical Chemistry, 98 (1994) 8053.

[33] E.M. Vass, M. Hävecker, S. Zafeiratos, D. Teschner, A. Knop-Gericke, R. Schlögl, Journal of Physics: Condensed Matter, 20 (2008) 184016.

[34] H. Bluhm, M. Hävecker, A. Knop-Gericke, M. Kiskinova, R. Schlögl, M. Salmeron, MRS Bulletin, 32 (2007) 1022.

[35] A. KnopGericke, E. Kleimenov, M. Hävecker, R. Blume, D. Teschner, S. Zafeiratos, R. Schlögl, V.I. Bukhtiyarov, V.V. Kaichev, I.P. Prosvirin, A.I. Nizovskii, H. Bluhm, A. Barinov, P. Dudin, M. Kiskinova, Chapter 4 Ray Photoelectron Spectroscopy for Investigation of Heterogeneous Catalytic Processes, in: C.G. Bruce, K. Helmut (Eds.) Advances in Catalysis, Academic Press, 2009, pp. 213.

[36] M. Salmeron, R. Schlögl, Surface Science Reports, 63 (2008) 169.

[37] S. Tanuma, C.J. Powell, D.R. Penn, Surface and Interface Analysis, 21 (1994) 165.

[38] J.J. Yeh, I. Lindau, Atomic Data and Nuclear Data Tables, 32 (1985) 1.
[39] D.L. Kaiser, R.L. Watters Jr., SRM 674b X-Ray Powder Diffraction Intensity Set for Quantitative Analysis by X-Ray Powder Diffraction, in, National Institute of Standards and Technology, U.S. Department of Commerce, Gaithersburg, 2007.

[40] Y.V. Belokopytov, K.M. Kholyavenko, S.V. Gerei, Journal of Catalysis, 60 (1979) 1.

[41] Q. Sun, Y. Fu, H. Yang, A. Auroux, J. Shen, Journal of Molecular Catalysis A: Chemical, 275 (2007) 183.

[42] A.A. Budneva, E.A. Paukshtis, A.A. Davydov, Reaction Kinetics and Catalysis Letters, 34 (1987) 63.

[43] E.M. Erenburg, T.V. Andrushkevich, G.Y. Popova, A.A. Davydov, V.M. Bondareva, Reaction Kinetics and Catalysis Letters, 12 (1979) 5.

[44] P. Concepcion, P. Botella, J.M.L. Nieto, Applied Catalysis, A: General, 278 (2004) 45.

[45] M. Baca, A. Pigamo, J.L. Dubois, J.M.M. Millet, Catalysis Communications, 6 (2005) 215.

[46] A. Kamper, A. Auroux, M. Baerns, Physical Chemistry Chemical Physics, 2 (2000) 1069.

[47] I. Langmuir, Journal of the American Chemical Society, 38 (1916) 2221.

[48] N. Cardona-Martinez, J.A. Dumesic, Applications of Adsorption Microcalorimetry to the Study of Heterogeneous Catalysis, in: H.P. D.D. Eley, B.W. Paul (Eds.) Advances in Catalysis, Academic Press, 1992, pp. 149.

[49] A.L. McClellan, H.F. Harnsberger, Journal of Colloid and Interface Science, 23 (1967) 577.

[50] S.J. Gregg, R. Stock, Transactions of the Faraday Society, 53 (1957) 1355.

[51] W. Ueda, D. Vitry, T. Katou, Catalysis Today, 99 (2005) 43.

[52] E. Balcells, F. Borgmeier, I. Grisstede, H.G. Lintz, F. Rosowski, Applied Catalysis, A: General, 266 (2004) 211.

[53] J.F. Moulder, W.F. Stickle, P.E. Sobol, K.D. Bomben, Handbook of X-ray Photoelectron Spectroscopy, PerkinElmer, USA, 1992.

[54] H. Al-Kandari, F. Al-Kharafi, A. Katrib, Catalysis Letters, 139 (2010) 134.

[55] B. Brox, I. Olefjord, Surface and Interface Analysis, 13 (1988) 3 .

[56] C. Wagner, A.V. Naumkin, A. Kraut-Vass, J.W. Allison, C.J. Powell, J.R. Rumble Jr., in: NIST X-ray Photoelectron Spectroscopy Database pp. Vers. 3.5.

[57] G.A. Sawatzky, D. Post, Physical Review B, 20 (1979) 1546.

[58] D.E. Ramaker, Critical Reviews in Solid State and Materials Sciences, 17 (1991) 211

[59] R. Weissmann, Solid State Communications, 31 (1979) 347.

[60] P. Ascarelli, G. Moretti, Surface and Interface Analysis, 7 (1985) 8.

[61] G. Brizuela, N. Castellani, M. Puentes, Surface and Interface Analysis, 18 (1992) 784.

[62] W.A. Goddard, III, K. Chenoweth, S. Pudar, A.C.T. Duin, M.J. Cheng, Topics in Catalysis, 50 (2008) 2.

[63] G. Franz, R.A. Sheldon, Oxidation, Wiley-VCH Verlag GmbH \& Co. KGaA, 2000. 